Sharif University of Technology
Scientia Iranica
SCIENTIA
IRAN Transactions B: Mechanical Engineering
www.scientiairanica.com

\title{
The application of suction and blowing in performance improvement of transonic airfoils with shock control bump
}

\author{
K. Mazaheri, A. Nejati* and K. Chaharlang Kiani \\ Center of Excellence in Aerospace Systems, Sharif University of Technology, Tehran, Iran.
}

Received 26 July 2015; received in revised form 30 January 2016; accepted 7 March 2016

KEYWORDS
Transonic airfoil;
Shock wave;
Drag reduction;
Shock control bump;
Suction;
Blowing;
Adjoint optimization;
Hybrid flow control
tools.

\section{Introduction}

Occurrence of different physical phenomena including shock waves, Shock Wave/Boundary Layer Interaction (SWBLI), buffeting, and shock oscillations make aircraft design in transonic flight regime one of the most challenging issues in aerodynamics. The concept of adaptive aerodynamic surfaces is proposed to achieve higher lift and lower drag coefficients, buffeting delay $[1,2]$, and improved flight maneuverability. Many different flow control methods, e.g. boundary layer suction/blowing, vortex generators, geometrical adap-

\footnotetext{
*. Corresponding author. Tel.: +982166164631 E-mail addresses: mazaheri@sharif.ir (K. Mazaheri); a_nejati@ae.sharif.ir (A. Nejati); kiarash@ae.sharif.ir (K. Chaharlang Kiani)
}

tation, cavities, and porous surfaces, have been widely studied to control the effects of shock waves in the transonic flight [3]. In 1999, Ashill and Fulker [4] introduced the idea of local wing deformation in the vicinity of the shock wave to reduce the strength of the shock wave. This was called a Shock Control Bump (SCB). Since then, this idea has been studied and developed by many researchers [5-10].

To increase applicability of SCBs in the transonic flight, two recent studies show that using optimized shape of the SCB after the drag divergence Mach number may significantly improve the aerodynamic performance of the transonic airfoils in off-design flight conditions $[5,6]$. It is verified that the SCB is more effective than many other flow control methods (e.g., the blowing, cavity, and the suction methods) [7]. Another study has shown that an SCB is more effective 
than the surface cooling or warming [8]. In [9], the performance of SCBs in many different flow conditions is investigated. Recently, many people have considered its hybrid performance in combination with other flow control schemes, such as blowing and suction. In [3], the use of suction upstream of the shock wave and in front of the SCB is studied. Recently, combination of suction with blowing has also been investigated [10].

This article studies the effects of suction and blowing on the physics of strong shock waves over SCBs, and improves their performance. The main factor affecting performance of an SCB in the transonic regime is the generation of vortical separated flow stimulated by tall SCBs. Here, we focus on improving SCB performance by boundary layer separation control. Shock Wave/Boundary Layer Interaction (SWBLI) usually results in rapid boundary layer separation. When the shock wave is strong enough, separation occurs right after the shock wave. Most recent optimization investigations focus on low transonic Mach numbers with a relatively weak shock wave, which do not stimulate a rapid boundary layer separation. Researchers usually only study the overall aerodynamic coefficients and efficiency, and neglect concern regarding the separated regions over the control devices. In this article, we also investigate boundary layer growth and separation after shock waves induced by the transonic flow with different Mach numbers. This brings a new insight to the physics of SCB and how and when it is practically effective. We show that this boundary layer analysis will significantly help us to design more effective hybrid flow control methods. The hybrid schemes are much more effective than simple flow control methods, since not only they improve the aerodynamic coefficients, but also they prevent formation of large separated flow regions, which is a serious concern for controlling the surface design.

Many elements of this research are new contributions to the subject of SCB design, including the application of suction/blowing for the vortical flow control, the physical analysis of the boundary layer structure around the suction/blowing region, and geometrical modeling of the suction/blowing channel (instead of the usual modeling based on simulated boundary conditions [11], which is certainly inappropriate for accurate simulation of boundary layer interactions). These are all applied to two benchmark transonic airfoils (i.e., NACA-64A010 and RAE-2822). We itemize contributions of this research as the following:
- Comparison of suction and blowing effects on the separated boundary layer induced by the SCB;

- Numerical modeling of the suction/blowing channel;

- A parametric study on the effect of the suction/blowing "location", the non-dimensional "mass flow", and "momentum" on the separated region;

- Quasi-optimization of HSS and HBS using a parametric study.

\section{Shock control bump}

Shock control bumps are used to reduce undesirable effects of strong shock waves over aerodynamic surfaces in transonic conditions. The bump geometry and its position are designed so that some isentropic compression waves are formed when flow moves upward the bump (Figure 1). Passing through these isentropic compression waves, the flow velocity is gradually reduced and the pressure is gradually increased (instead of sudden changes). Downhill the bump, we have some expansion waves and then, the flow adjacent to the wall passes through a weakened shock wave. The generated wave drag in this process is less than that induced by the original normal shock.

The performance of the bumped airfoil is very sensitive to shape and location of the bump. Extensive studies are devoted to the design of its shape and location [12]. This, of course, is a function of airfoil shape and flight conditions. These studies may be divided into two different categories: (a) parametric studies, e.g. [12]; and, (b) performance improvements, e.g. [13]. The idea of SCB is also extended to 3D wing applications, e.g., Wong et al. [14] have studied the drag reduction of a transonic plane via an SCB. However, since most SWBLI interactions are visible in a 2D analysis, for simplicity, we restrict ourselves to two-dimensional analysis here.

\section{Suction and blowing on an airfoil surface}

The flow suction or blowing over an airfoil surface is used to give energy or remove stagnant fluid in the boundary layer, to overcome the adverse pressure gradient effects, and to prevent boundary layer growth and detachment after the shock wave. Suction and blowing have been used for a long time to control the boundary layer separation. The main purpose for using suction is to remove the low-energy boundary layer;

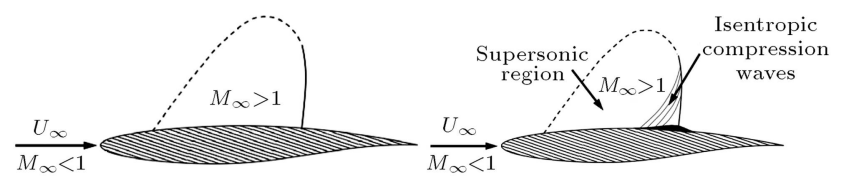

Figure 1. Effect of shock control bump on the compressible flow over a supercritical airfoil. 
while using blowing, we energize the boundary layer and change the velocity profile. This will enhance the velocity profile and delay the occurrence of an inflection point and separation from the wall.

Suction has a significant effect on the aerodynamic performance. Basically, appropriate flow suction can control (decrease) the growth of boundary layer thickness, and may result in total drag reduction by reducing drag due to viscous effects. In ONERA, Le Balleur et al. [15] showed that the flow suction before the shock wave could reduce the total drag of RAE5225 airfoil by $5.1 \%$; but, if located after the shock, it would not reduce the wave drag. Another example of the drag reduction using flow suction upstream of the shock wave is the experimental research performed at Karlsruhe University [3] on DRA-2303 airfoil. A comprehensive study was performed on the location of the suction region as well as the effects of different suction mass flow rates. The main finding of this study was that the total drag reduction might vary from $2.5 \%$ up to $4.9 \%$, based on values of flow and location parameters.

In 2006, Vadillo et al. [11] numerically investigated the reduction of shock wave strength and other undesirable effects of SWBLI in transonic flow regimes through usage of the boundary layer suction. They showed that by variations of amplitude, frequency, mass flow, and location, one can improve the aerodynamic coefficients including lift, drag, and bending moment.

In [16], Pehlivanoglu et al. used suction and blowing to improve the aerodynamic performance of transonic airfoils. It is observed that the aerodynamic performance increases by over $20 \%$ as a result of optimizing the location, angle, and mass flow coefficient of the suction and blowing control ports on the airfoil surface at transonic speeds. Pehlivanoglu and Yagiz [17] used the active and passive flow control methods to improve the aerodynamic performance of transonic airfoils. In this research, they optimized the suction and blowing parameters with genetic algorithm.

\section{Hybrid flow control methods}

One expects that simultaneous usage of two or more flow control methods (e.g., shock control bump with suction or blowing), shown schematically in Figure 2, would result in a better aerodynamic performance. The advantage of using SCBs with suction is that suction upstream of the shock wave gives momentum to the boundary layer and makes it thinner, thereby preventing flow separation and reducing losses due to viscous effects initiated by tall bumps and SWBLI. By importing momentum to the boundary layer, the blowing after the shock wave can also prevent the boundary layer thickening and separation after the bump and, consequently, reduce the drag coefficient.

Birkemeyer [18] equipped the swept ADIF wing with SCB and flow suction upstream of the shock wave, and investigated the aerodynamic performance of the wing with different angles of attack. Results showed that SCB alone reduced the total drag only $8 \%$, but along with moderate suction resulted in $12 \%$ reduction in the total drag, while by strong suction reduced it by $22 \%$.

In 2000, Qin et al. [19] released results of some of their parametric studies on flow control methods in transonic speeds. Three different control schemes, i.e. suction, blowing, and SCB, were investigated on an RAE-5243 airfoil to understand their effects on SWBLI. They showed that suction and SCB might increase the aerodynamic efficiency independently. Blowing around the shock wave location may reduce the shock strength, but it may improve the aerodynamic performance only when applied near the trailing edge. This study was extended in 2004 by Qin et al. [7]. They did not report details of their parametric study and only showed the best combination. They also did not discuss effects of independent parameters (they only provided a partial discussion on the height and position of SCB).

Yagiz et al. [10] have also extensively investigated effects of flow control schemes to improve the performance of RAE-5243. Using the gradient optimization algorithms, they have been able to decrease the drag coefficient by $3.94 \%$ and increase the lift coefficient by $5.04 \%$. They used an efficient gradient-based optimization technique to optimize the $2 \mathrm{D}$ bump parameters including length, maximum height, bump position via shock location, and crest position via bump and also the jet actuation parameters such as the mass flow coefficient, suction/blowing angle, and the actuation location over the upper surface of the airfoil. Their results indicate that the enhancement in the lift, the decrement in the total drag, and the mitigation of the shock strength can be obtained by using a 2D contour bump. At the same time, the surface suction decreases the drag with an increment in lift value.

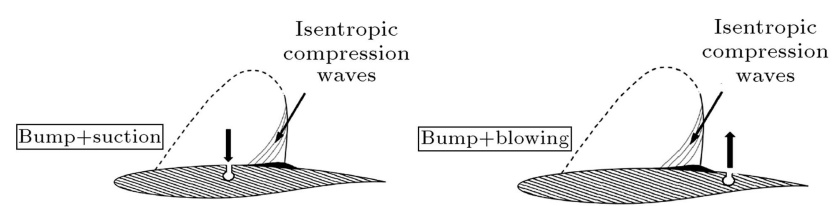

Figure 2. The schematics of the suction and blowing on a supercritical airfoil with bump. 


\section{Problem definition}

Here, we investigate the simultaneous usage of SCBs with two other flow control schemes. First, we use an optimization algorithm to minimize the drag coefficient by optimization of the bump geometry parameters for two benchmark supercritical airfoils in off-design conditions, i.e. RAE-2822 and NACA-64A010 airfoils. Then, we add suction or blowing to enhance the SCB performance when the flow is separated because of relatively larger bumps. For comparison purposes, the original aerodynamic coefficients for several different off-design flow conditions are shown in Tables 1 and 2 . Throughout this article, we use these flight conditions as the basis for our comparisons. Here, $C d_{v}$ and $C d_{p}$ denote the friction and the pressure drags, respectively. Figure 3 shows the drag divergence diagram for RAE2822 .

In the case of suction and blowing, mass is removed from or injected to the flow around the airfoil. From the conservation of momentum, or Newton's second law, there will be a force acting on the aerofoil in addition to the pressure and skin-friction forces acting on the external surfaces of the aerofoil. In these cases, the present studies are limited only to isolated effects of suction and blowing on the forces acting on the aerofoil. Therefore, there is no contribution to the lift and drag forces from the sucked or injected mass flow.

\section{Modeling the bump geometry}

In this research, the Sine-function with minor improvement with respect to [12] is used to model the bump geometry. Hicks-Henne (Eq. (1)) is a sine-function that is able to create bumps with different heights, slopes, asymmetries, and lengths. One of the features of this function is that the slope of the curve is equal to zero

Table 1. Four flight conditions for optimization;

RAE-2822, $\operatorname{Re}_{\infty}=7.6 \times 10^{6}$, and $\alpha=1.5$.

\begin{tabular}{ccccccc}
\hline $\begin{array}{c}\text { Flight } \\
\text { condition }\end{array}$ & $\boldsymbol{M}_{\infty}$ & $\boldsymbol{C l}$ & $\boldsymbol{C d}_{\boldsymbol{v}}$ & $\boldsymbol{C d}_{\boldsymbol{p}}$ & $\boldsymbol{C d}_{\boldsymbol{t}}$ & $\boldsymbol{L} / \boldsymbol{D}$ \\
\hline 1 & 0.75 & 0.554 & 0.0056 & 0.0077 & 0.0133 & 41.6 \\
2 & 0.76 & 0.542 & 0.0055 & 0.0105 & 0.0160 & 33.9 \\
3 & 0.78 & 0.487 & 0.0053 & 0.017 & 0.0223 & 21.8 \\
4 & 0.79 & 0.446 & 0.0052 & 0.0199 & 0.0251 & 17.8 \\
\hline
\end{tabular}

Table 2. Three flight conditions for optimization; NACA-64A010, $\operatorname{Re}_{\infty}=7.6 \times 10^{6}$, and $\alpha=2.0$.

\begin{tabular}{ccccccc}
\hline $\begin{array}{c}\text { Flight } \\
\text { condition }\end{array}$ & $\boldsymbol{M}_{\infty}$ & $\boldsymbol{C l}$ & $\boldsymbol{C d}$ & $\boldsymbol{C d} \boldsymbol{d}_{\boldsymbol{p}}$ & $\boldsymbol{C d}_{\boldsymbol{t}}$ & $\boldsymbol{L} / \boldsymbol{D}$ \\
\hline 1 & 0.77 & 0.394 & 0.0055 & 0.0069 & 0.0124 & 31.8 \\
2 & 0.786 & 0.379 & 0.0054 & 0.0106 & 0.0160 & 23.8 \\
3 & 0.81 & 0.345 & 0.0052 & 0.0181 & 0.0233 & 14.8 \\
\hline
\end{tabular}

at both ends $\left(f^{\prime}(0)=f^{\prime}(1)=0\right)$. This prevents formation of any discontinuity between the airfoil and the bump. Eq. (1) describes the Hicks-Henne function. In this equation, $h_{B}$ is the maximum bump height, $t$ represents the slope parameter, and $x$ represents the non-dimensional length parameter with respect to the bump length $\left(l_{B}\right)$. All the geometrical details are shown in Figure 4.

$$
f(x)=h_{B}\left(\sin \left(\pi x^{m}\right)\right)^{t}, \quad 0 \leq x \leq 1 .
$$

In Eq. (1), the parameter $m$, defined by Eq. (2), is used to create asymmetric bumps. Here, $C_{B} / l_{B}$ represents the degree of asymmetry and is in the range of $(0,1)$, see Figure 4 . $C_{B} / l_{B}=0.5$ represents a symmetric bump.

$$
m=\frac{\ln (0.5)}{\ln \left(c_{B} / l_{B}\right)} .
$$

The other important parameter is $x_{0}$, the beginning of the bump on the airfoil surface (Figure 4). The range of variations in the bump geometry parameters in this article is given below (all the variables are nondimensional with respect to the airfoil chord length).

$\left\{\begin{array}{l}0 \leq h_{B} \leq 0.01 c \\ 0.3 \leq x_{0} / l_{B} \leq 0.55 \\ 0.4 \leq c_{B} / l_{B} \leq 0.85 \\ 0.5 \leq t \leq 2 \\ 0.15 \leq l_{B} \leq 0.3\end{array}\right.$

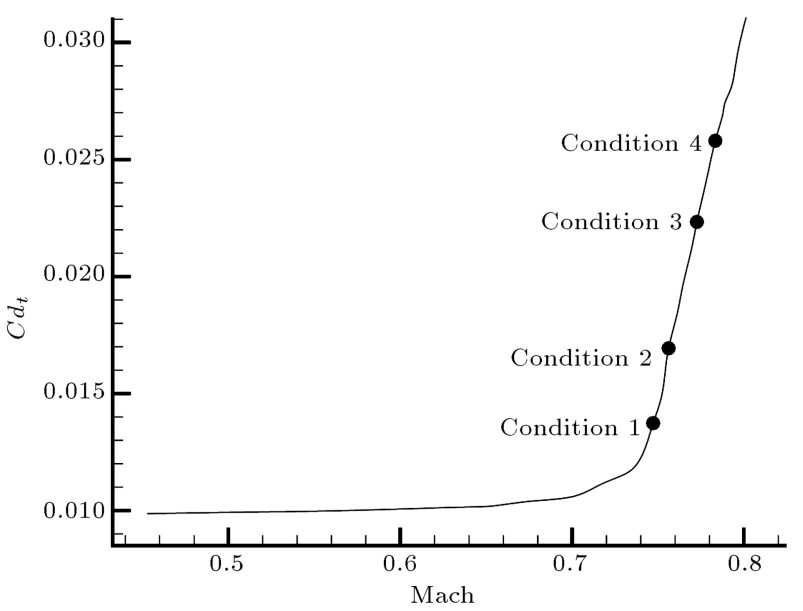

Figure 3. The drag divergence diagram for RAE-2822 at $\alpha=1.5^{\circ}$.

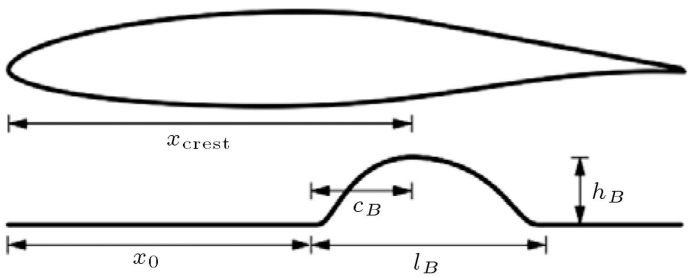

Figure 4. The geometrical design parameters for shock control bump. 
Limits of different design variables are selected by considering various references such as $[12,13]$. In the optimization process, in order to reach a more realistic design, $15 \%$ of the airfoil trailing part is devoted to the flap; thus, the bump should be located ahead of this region.

\section{Governing equations of the flow}

The integral form of the governing equations for each computational cell is introduced in Eq. (4). Here, w, $\mathbf{f}_{\mathbf{c}}$, and $\mathbf{f}_{\mathbf{v}}$ stand for the conservative variable vector, the convection flux vector, and the viscous flux vector, respectively. In Eq. (5), the conservative variable vector in 2-D space is shown. Here, $\rho$ is density, $u$ and $v$ are velocity components, $E$ is total energy, $H$ is total enthalpy, $V$ (contra-variant velocity) is the velocity normal to each cell face, and $\boldsymbol{\tau}$ is tensor of shear stress.

$$
\begin{aligned}
& \frac{\partial}{\partial t} \int_{\Omega} \overrightarrow{\mathbf{U}} d \Omega+\oint_{\partial \Omega}\left(\overrightarrow{\mathbf{f}_{c}}-\overrightarrow{\mathbf{f}_{v}}\right) d s=0, \\
& \overrightarrow{\mathbf{U}}=\left[\begin{array}{c}
\rho \\
\rho u \\
\rho v \\
\rho E
\end{array}\right], \quad \overrightarrow{\mathbf{f}_{c}}=\left[\begin{array}{c}
\rho V \\
\rho u V+n_{x} p \\
\rho v V+n_{y} p \\
\rho H V
\end{array}\right], \\
& \overrightarrow{\mathbf{f}_{v}}=\left[\begin{array}{c}
0 \\
n_{x} \tau_{x x}+n_{y} \tau_{x y} \\
n_{x} \tau_{y x}+n_{y} \tau_{y y} \\
n_{x} \Theta_{x}+n_{y} \Theta_{y}
\end{array}\right] .
\end{aligned}
$$

$V, \Theta_{x}$, and $\Theta_{y}$ are defined in Eqs. (6) and (7) while $n_{x}$ and $n_{y}$ are components of the unit vector perpendicular to the cell faces.

$$
\begin{aligned}
& V=n_{x} u+n_{y} v, \\
& \Theta_{x}=u \tau_{x x}+v \tau_{x y}+k \frac{\partial T}{\partial x}, \\
& \Theta_{y}=u \tau_{y x}+v \tau_{y y}+k \frac{\partial T}{\partial y} .
\end{aligned}
$$

Here, a finite volume method is used for flow field discretization. The flux across each cell face is approximated using Roe flux difference splitting method. $\mathbf{f}_{c}$ (convection flux vector) is computed for each cell face by:

$$
\begin{aligned}
\left(\overrightarrow{\mathbf{f}}_{c}\right)_{I+1 / 2}= & \frac{1}{2}\left[\overrightarrow{\mathbf{f}}_{c}\left(\overrightarrow{\mathbf{U}}_{R}\right)+\overrightarrow{\mathbf{f}}_{c}\left(\overrightarrow{\mathbf{U}}_{L}\right)\right. \\
& \left.-\left|\overline{\mathbf{A}}_{R o e}\right|_{I+1 / 2}\left(\overrightarrow{\mathbf{U}}_{R}-\overrightarrow{\mathbf{U}}_{L}\right)\right] .
\end{aligned}
$$

Here, $\left|\mathbf{A}_{\text {Roe }}\right|_{I+1 / 2}$ is the Jacobean of the convection flux vector and is computed as follows:

$$
\begin{aligned}
& \left|\widetilde{\mathbf{A}}_{R o e}\right|_{I+1 / 2}\left(\overrightarrow{\mathbf{U}}_{R}-\overrightarrow{\mathbf{U}}_{L}\right)=\left|\Delta \overrightarrow{\mathbf{f}}_{1}\right|+\left|\Delta \overrightarrow{\mathbf{f}}_{2,3.4}\right|+\left|\Delta \overrightarrow{\mathbf{f}}_{5}\right|, \\
& \left|\Delta \overrightarrow{\mathbf{f}}_{1}\right|=|\tilde{V}-\tilde{c}|\left(\frac{\Delta p-\tilde{\rho} \tilde{c} \Delta V}{2 \tilde{c}^{2}}\right)\left[\begin{array}{c}
1 \\
\tilde{u}-\tilde{c} n_{x} \\
\tilde{v}-\tilde{c} n_{y} \\
\tilde{H}-\tilde{c} \tilde{V}
\end{array}\right], \\
& \left|\Delta \overrightarrow{\mathbf{f}}_{5}\right|=|\tilde{V}+\tilde{c}|\left(\frac{\Delta p+\tilde{\rho} \tilde{c} \Delta V}{2 \tilde{c}^{2}}\right)\left[\begin{array}{c}
1 \\
\tilde{u}+\tilde{c} n_{x} \\
\tilde{v}+\tilde{c} n_{y} \\
\tilde{H}+\tilde{c} \tilde{V}
\end{array}\right], \\
& \left|\Delta \overrightarrow{\mathbf{f}}_{2,3,4}\right|=|\tilde{V}|\left(\Delta \rho-\frac{\Delta p}{\tilde{c}^{2}}\right)\left[\begin{array}{c}
1 \\
\tilde{u} \\
\tilde{v} \\
\frac{\tilde{q}^{2}}{2}
\end{array}\right] \\
& +\tilde{\rho}|\tilde{V}|\left[\begin{array}{c}
0 \\
\Delta u-\Delta V n_{x} \\
\Delta v-\Delta V n_{y} \\
\tilde{u} \Delta u+\tilde{v} \Delta u-\tilde{V} \Delta V
\end{array}\right] .
\end{aligned}
$$

Here, the $(\Delta)$ operator is defined as $\Delta(\mathbf{\square})=$ $R-$ (ם) ${ }_{L}$, where $R$ and $L$ denote the right and the left sides of each cell face, respectively. For more details about the Roe averaged variables, please see [20]. The second order of accuracy is achieved by MUSCL scheme [20]:

$$
\begin{aligned}
& U_{R}=U_{I+1}-\frac{1}{2} \delta_{R}, \\
& U_{L}=U_{I}+\frac{1}{2} \delta_{L} \\
& \delta=\frac{a\left(b^{2}+\varepsilon\right)+b\left(a^{2}+\varepsilon\right)}{a^{2}+b^{2}+2 \varepsilon} \\
& a_{R}=\Delta_{+} U_{I+1}, \quad b_{R}=\Delta_{-} U_{I+1}, \\
& a_{L}=\Delta_{+} U_{I}, \quad b_{L}=\Delta_{-} U_{I}, \\
& \Delta_{+} U_{I}=U_{I+1}-U_{I}, \\
& \Delta_{-} U_{I}=U_{I}-U_{I-1} .
\end{aligned}
$$

Here, $I$ denotes the cell number, while $R$ and $L$ subscripts denote the properties exactly over the right and left sides of each cell face. In Eqs. (13), (14), and (15), $U$ can be any flow variable. The equations for $k-\omega$ turbulence modeling in the flow field are based on Eqs. (16) and (17) [21]. 


$$
\begin{aligned}
\frac{\partial}{\partial t}(\rho K) & +\frac{\partial}{\partial x_{i}}\left(\rho K u_{i}\right)=\frac{\partial}{\partial x_{j}}\left[\left(\mu+\frac{\mu_{t}}{\sigma_{k}}\right) \frac{\partial K}{\partial x_{j}}\right] \\
& +G_{k}-Y_{k}+S_{k} \\
\frac{\partial}{\partial t}(\rho \omega) & +\frac{\partial}{\partial x_{i}}\left(\rho \omega u_{i}\right)=\frac{\partial}{\partial x_{j}}\left[\left(\mu+\frac{\mu_{t}}{\sigma_{\omega}}\right) \frac{\partial \omega}{\partial x_{j}}\right] \\
& +G_{\omega}-Y_{\omega}+S_{\omega} .
\end{aligned}
$$

Here, subscripts $k$ and $\omega$ denote variables associated with the turbulence energy and the specific dissipation rate.

\section{Boundary conditions}

The free stream conditions are applied as the far field boundary conditions. A no-slip condition is used on the airfoil surface and the channel walls (see Figure 5). Over the suction or blowing regions, the average velocity of the inlet/outlet velocity profiles is defined as:

$$
U_{\text {ave }}=\frac{m^{\bullet}}{\sum_{L_{\text {suction }}} \rho_{s b} \Delta s},
$$

where subscript $s b$ denotes the channel inlet, and the non-dimensional mass flow is defined as:

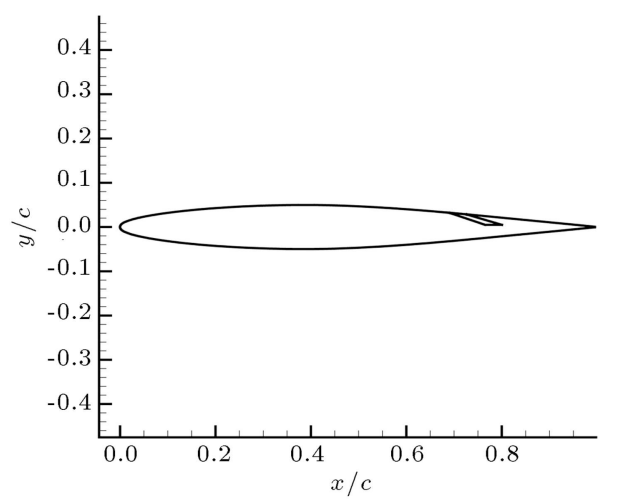

Figure 5. The suction channel over airfoil NACA-64A010 at $x / c=0.69$.
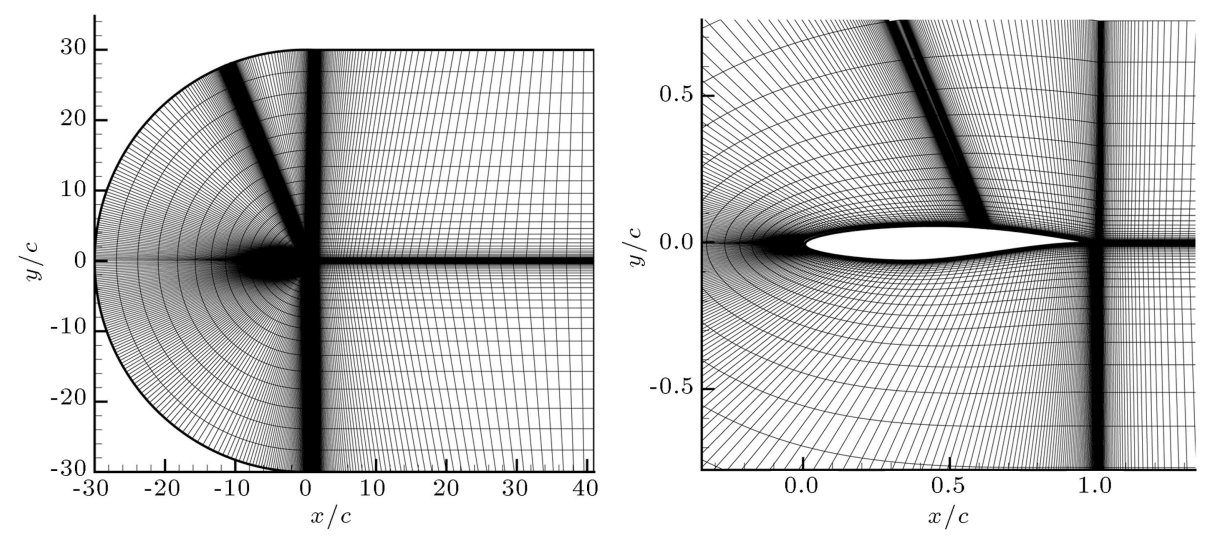

Figure 6. The sample grid generated around RAE-2822 airfoil.
In the above, $c$ is the chord. For suction, $C_{Q}$ is negative and it is positive for blowing. In the exit of channel, pressure outlet or inlet boundary condition is implemented.

\section{Validation of the flow solver}

Here, a 2D finite volume Navier-stokes RANS solver, which is developed at CEAS (Center of Excellence in Aerospace Systems, Sharif University of Technology), is used as flow solver [22]. To validate the flow solver, transonic flow around a supercritical airfoil RAE-2822 is simulated on $4 \times 3.4 \mathrm{GHz}$ CPUs. The flow conditions are Mach number $\left(M_{\infty}=0.75\right)$, the Reynolds number $\left(\operatorname{Re}_{\infty}=6.2 \times 10^{6}\right)$, and the angle of attack $\left(\alpha=3.03^{\circ}\right)$. The generated C-type mesh is shown in Figure 6 . Using grid independency study shown in Table 3 , an acceptable grid is chosen that includes 300 nodes on the airfoil surface, 100 nodes in the wake region, and 75 nodes in the vertical direction (see Table 3 ). The aerodynamic coefficients, distribution of the surface pressure coefficient, and the skin friction coefficient, compared with the experimental results in [23] are respectively presented in Table 3 and Figure 7 .

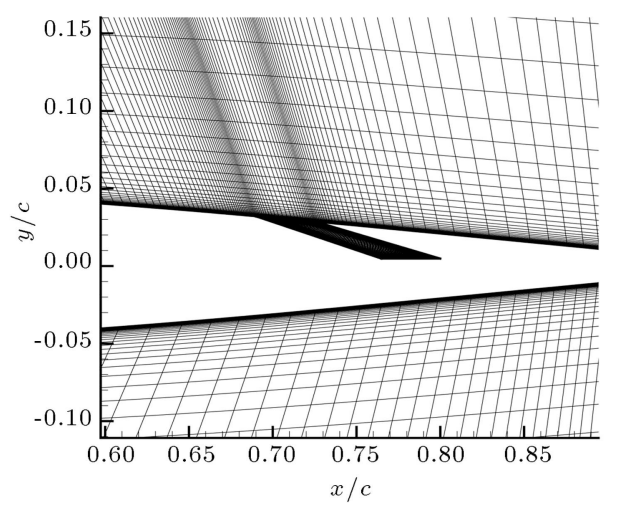


Table 3. The validation data for RAE-2822 airfoil.

\begin{tabular}{cccccccc}
\hline & $\begin{array}{c}\text { Coarse } \\
\text { grid-1 }\end{array}$ & $\begin{array}{c}\text { Coarse } \\
\text { grid-2 }\end{array}$ & $\begin{array}{c}\text { Coarse } \\
\text { grid-3 }\end{array}$ & $\begin{array}{c}\text { Fine } \\
\text { grid-1 }\end{array}$ & $\begin{array}{c}\text { Fine } \\
\text { grid-2 }\end{array}$ & $\begin{array}{c}\text { Exp. results } \\
{[\mathbf{2 3}]}\end{array}$ & $\begin{array}{c}\text { Num. results } \\
{[\mathbf{2 3}]}\end{array}$ \\
\hline Number of cells & 23800 & 26200 & 30700 & 35200 & 37500 & - & 16384 \\
$\boldsymbol{C l}$ & 0.744 & 0.743 & 0.743 & 0.744 & 0.743 & 0.742 & 0.743 \\
$\boldsymbol{C d}$ & 0.0277 & 0.0269 & 0.0262 & 0.0253 & 0.0251 & 0.0242 & 0.0255 \\
\hline
\end{tabular}
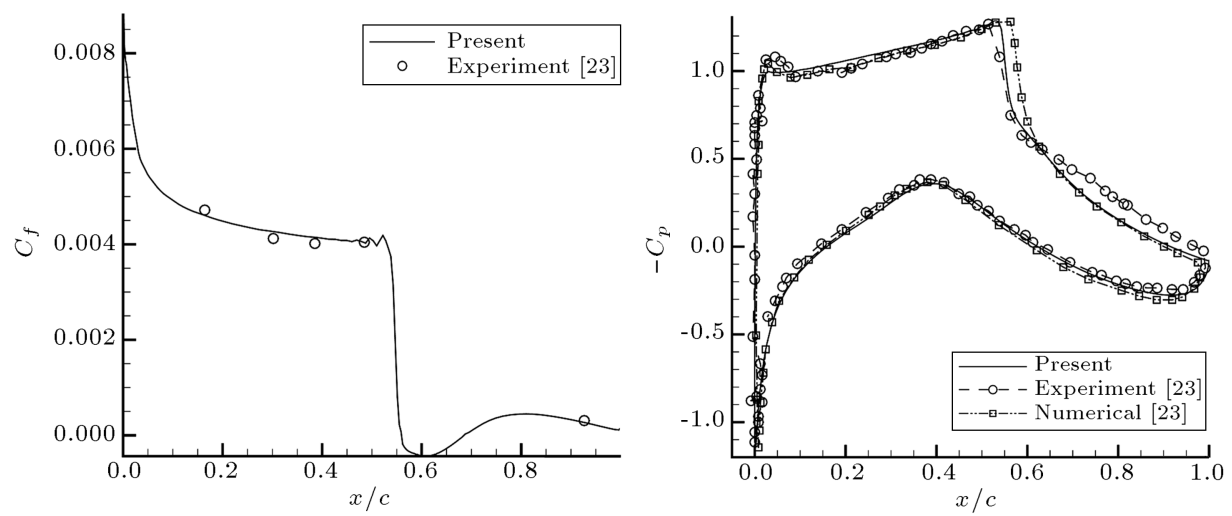

Figure 7. The pressure and the skin friction coefficient distribution for RAE-2822 airfoil.

\section{Modeling suction/blowing on the airfoil surface}

To model suction or blowing, a channel is used over the airfoil surface, as shown in Figure 5, and, using a pressure difference between its inlet and outlet, the flow is sucked in or blown out of the airfoil. The channel geometry includes three main parameters: $x_{s / b}, L_{s / b}$, and $\Theta_{s / b} . \quad x_{s / b}$ denotes the distance between the suction/blowing initial point and the leading edge. $L_{s / b}$ is the width of the entrance channel (these two parameters are non-dimensionalized with the airfoil chord). $\Theta_{s / b}$ is the suction/blowing inclination angle.

As an example, the NACA-64A010 airfoil with suction parameters $x_{s / b}=0.69 \mathrm{c}$ and $L_{s / b}=0.025 \mathrm{c}$ is shown in Figure 5. The suction flow angle, $\Theta_{s / b}$, is $-20^{\circ}$ with respect to the chord line. A multi-block grid is used; the first block consists of the flow around the airfoil and the second block includes the region inside the channel. After the grid independency study, comparison of the lift and the drag coefficients (Mach number: $M_{\infty}=0.78$, Reynolds number: $\operatorname{Re}_{\infty}=$ $2.9 \times 10^{6}$, and angle of attack: $\alpha=0.5^{\circ}$ ) with the numerical and the experimental results given in [7] is shown in Table 4. The non-dimensional mass flow equals $C_{Q}=-0.00225$ [7].

\section{The optimization results}

In the transonic flow, the pressure coefficient distribution on the upper surface is highly sensitive to the surface shape changes and this sensitivity makes the optimization scheme very effective. Thus, we use a very precise optimization algorithm for optimizing the shape of the wall (bump) and a much simpler optimization algorithm for suction and blowing in the next section.

In this research, the gradient-based steepest descent algorithm is used to find the optimum point. Therefore, minus of the gradient vector shows the optimization direction. The optimization process begins by a guess of the initial values of design variables. Then, in a repetitive process, we proceed through the maximum descent direction of the cost function to reach the optimum point (for details on the steepest descent method, see [5]). To apply geometrical constraints to our design parameters, we have used external

Table 4. The validation data for NACA-64A010 airfoil including suction.

\begin{tabular}{cccccccc}
\hline & $\begin{array}{c}\text { Coarse } \\
\text { grid-1 }\end{array}$ & $\begin{array}{c}\text { Coarse } \\
\text { grid-2 }\end{array}$ & $\begin{array}{c}\text { Coarse } \\
\text { grid-3 }\end{array}$ & $\begin{array}{c}\text { Fine } \\
\text { grid-1 }\end{array}$ & $\begin{array}{c}\text { Fine } \\
\text { grid-2 }\end{array}$ & $\begin{array}{c}\text { Exp. results } \\
{[7]}\end{array}$ & $\begin{array}{c}\text { Num. results } \\
{[7]}\end{array}$ \\
\hline Number of grid cells & 24500 & 26500 & 29500 & 40200 & 42500 & - & 12285 \\
$\boldsymbol{C l}$ & 0.281 & 0.28 & 0.281 & 0.282 & 0.282 & 0.24 & 0.279 \\
$\boldsymbol{C} \boldsymbol{d}$ & 0.016 & 0.015 & 0.0135 & 0.0128 & 0.0125 & 0.013 & 0.014 \\
\hline
\end{tabular}


Table 5. The initial values for design parameters.

\begin{tabular}{lccccc}
\hline $\begin{array}{l}\text { Design } \\
\text { parameter }\end{array}$ & $\boldsymbol{x}_{\mathbf{0}} / \boldsymbol{c}$ & $\boldsymbol{c}_{\boldsymbol{B}} / \boldsymbol{c}$ & $\boldsymbol{t}$ & $\boldsymbol{l}_{\boldsymbol{B}} / \boldsymbol{c}$ & $\boldsymbol{h}_{\boldsymbol{B}} / \boldsymbol{c}$ \\
\hline Values & 0.5 & 0.5 & 1.0 & 0.2 & 0.0 \\
\hline
\end{tabular}

Table 6. The bump optimization results for RAE- 2822 .

\begin{tabular}{cccccc}
\hline $\begin{array}{c}\text { Flow } \\
\text { condition }\end{array}$ & $\boldsymbol{x}_{\boldsymbol{0}} / \boldsymbol{c}$ & $\boldsymbol{c}_{\boldsymbol{B}} / \boldsymbol{c}$ & $\boldsymbol{t}$ & $\boldsymbol{l}_{\boldsymbol{B}} / \boldsymbol{c}$ & $\boldsymbol{h}_{\boldsymbol{B}} / \boldsymbol{c}$ \\
\hline 1 & 0.503 & 0.536 & 1.289 & 0.261 & 0.00439 \\
2 & 0.523 & 0.522 & 1.244 & 0.303 & 0.00847 \\
3 & 0.541 & 0.544 & 1.223 & 0.299 & 0.00991 \\
4 & 0.530 & 0.532 & 1.238 & 0.308 & 0.0101 \\
\hline
\end{tabular}

Table 7. The bump optimization results for NACA-64A010.

\begin{tabular}{cccccc}
\hline $\begin{array}{c}\text { Flow } \\
\text { condition }\end{array}$ & $\boldsymbol{x}_{\mathbf{0}} / \boldsymbol{c}$ & $\boldsymbol{c}_{\boldsymbol{B}} / \boldsymbol{c}$ & $\boldsymbol{t}$ & $\boldsymbol{l}_{\boldsymbol{B}} / \boldsymbol{c}$ & $\boldsymbol{h}_{\boldsymbol{B}} / \boldsymbol{c}$ \\
\hline 1 & 0.375 & 0.567 & 0.983 & 0.296 & 0.00632 \\
2 & 0.444 & 0.622 & 0.789 & 0.298 & 0.00998 \\
3 & 0.471 & 0.578 & 0.587 & 0.298 & 0.0104 \\
\hline
\end{tabular}

penalty function scheme based on [5]. Validation of the optimization algorithm is straightforward [5] and not repeated here. One needs to use an inverse design problem. The common practice is to use a conventional airfoil, modeling its surface with a few design parameters. Then, the model is perturbed and given the correct pressure distribution of the original airfoil; the algorithm should find the airfoil shape in a few optimization cycles.

For each flight condition stated in Tables 1 and 2, we use an adjoint gradient based optimization algorithm (based on [24]) to find optimum values for the bump parameters towards the least drag coefficient. Table 5 shows the initial values of the selected five design parameters. The angle of attack is fixed and the initial bump has zero height. The optimization results are given in Tables 6 to 9 . As expected, increase in the free stream Mach number results in increasing bump height.

Respective comparison of Tables 8 and 9 with
Tables 1 and 2 shows that the SCB reduces the drag coefficient and increases the aerodynamic efficiency in all flight conditions. Based on these tables, one observes that for both airfoils, the maximum aerodynamic efficiency improvement happens in the flight condition 2. For the RAE-2822 airfoil in conditions 3 and 4 and for NACA-64A010 airfoil in the third condition, despite the expected decrease in the drag coefficient, due to the flow separation after the bump, the lift coefficient is not increased significantly. Comparison of two airfoils shows that the relative effect of the bump is higher for the thinner airfoil (NACA64A010).

Figure 8 shows the pressure contours along with the flow streamlines around RAE-2822 airfoil with SCB for all flight conditions. One observes that for flight conditions 3 and 4, the greater height of the bump encourages geometrical flow separation right over the bump and this increases the pressure above the airfoil and decreases the lift coefficient and SCB performance. We see the same phenomenon for NACA-64A010 airfoil in Figure 9. As the free stream Mach number increases, the SCB performance decreases due to the formation of a large vortical separated region after the bump. In the next sections, we use flow suction/blowing to minimize or eliminate the vortical separated region after the bump to improve the performance of the SCB for RAE-2822 airfoil in the flight condition 4 and for NACA-64A010 airfoil in the flight condition 3. For this study, we use the optimized shape of the SCB for these flight conditions. Please note that the SCB has been "optimized" for a single off-design condition and its shape is frozen in the next sections to find near optimum values of suction/blowing in the flight condition 4 for RAE-2822 and in the flight condition 3 for NACA-64A010 airfoil. Studying the performance of the SCB-only case in other off-design conditions or in on-design conditions is out of scope of this article and they are studied in other articles $[5,6]$.

\section{The application of suction/blowing for RAE-2822}

After optimizing the SCB geometry on RAE-2822 in the previous section, suction/blowing is added to improve the bump performance for the flight condi-

Table 8. The performance optimization results for RAE-2822 with the optimized bump.

\begin{tabular}{cccccccccc}
\hline $\begin{array}{c}\text { Flight } \\
\text { condition }\end{array}$ & $\boldsymbol{M}$ & $\boldsymbol{C l}$ & $\boldsymbol{C} \boldsymbol{d}_{\boldsymbol{v}}$ & $\boldsymbol{C} \boldsymbol{d}_{\boldsymbol{p}}$ & $\boldsymbol{C d} \boldsymbol{d}_{\boldsymbol{t}}$ & $\boldsymbol{L} / \boldsymbol{D}$ & $\% \boldsymbol{C l}$ & $-\% \Delta \boldsymbol{C d}$ & $\% \Delta \boldsymbol{L} / \boldsymbol{D}$ \\
\hline 1 & 0.75 & 0.575 & 0.0057 & 0.0064 & 0.0120 & 47.8 & 3.79 & 9.77 & 14.9 \\
2 & 0.76 & 0.576 & 0.0056 & 0.0081 & 0.0137 & 42.1 & 6.27 & 14.4 & 24.4 \\
3 & 0.78 & 0.496 & 0.0054 & 0.0134 & 0.0187 & 26.5 & 1.85 & 15.8 & 21.5 \\
4 & 0.79 & 0.438 & 0.0053 & 0.016 & 0.0212 & 20.7 & -1.79 & 15.5 & 16.3 \\
\hline
\end{tabular}


Table 9. The performance optimization results for NACA-64A010 with the optimized bump.

\begin{tabular}{cccccccccc}
\hline $\begin{array}{c}\text { Flight } \\
\text { condition }\end{array}$ & $\boldsymbol{M}$ & $\boldsymbol{C l}$ & $\boldsymbol{C d} \boldsymbol{d}_{\boldsymbol{v}}$ & $\boldsymbol{C d}_{\boldsymbol{p}}$ & $\boldsymbol{C d}$ & $\boldsymbol{L} / \boldsymbol{D}$ & $\% \Delta \boldsymbol{C l}$ & $-\% \Delta \boldsymbol{C d}$ & $\% \Delta \boldsymbol{L} / \boldsymbol{D}$ \\
\hline 1 & 0.77 & 0.415 & 0.0056 & 0.00545 & 0.011 & 37.7 & 5.32 & 11.3 & 18.5 \\
2 & 0.786 & 0.422 & 0.0055 & 0.00774 & 0.0132 & 32.0 & 11.3 & 17.5 & 35.0 \\
3 & 0.81 & 0.342 & 0.0053 & 0.0144 & 0.0196 & 17.5 & -0.869 & 15.9 & 18.2 \\
\hline
\end{tabular}

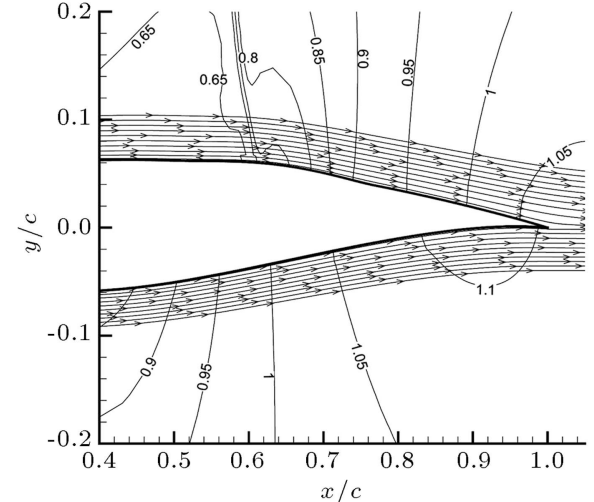

(a)

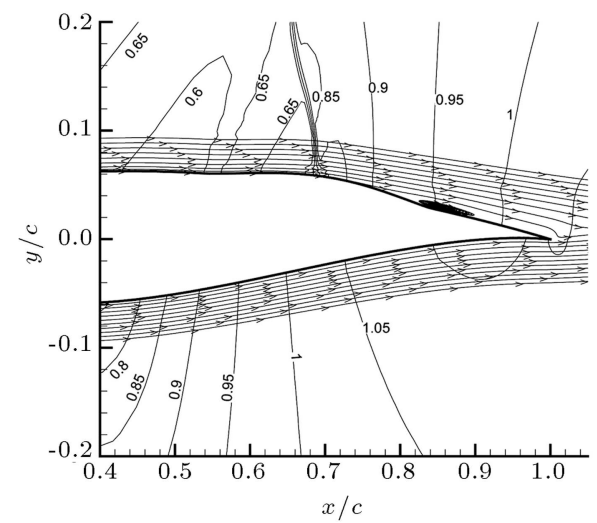

(c)

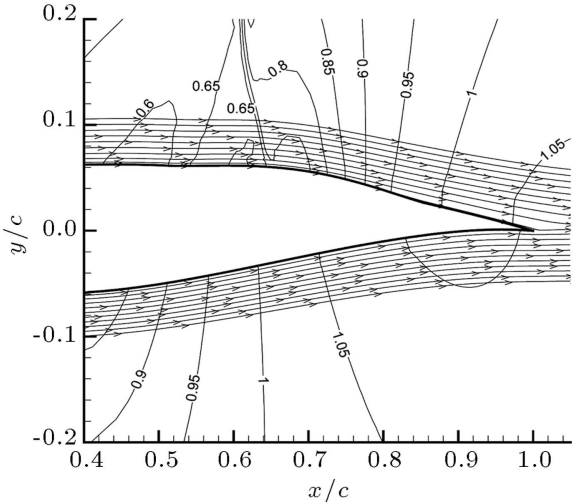

(b)

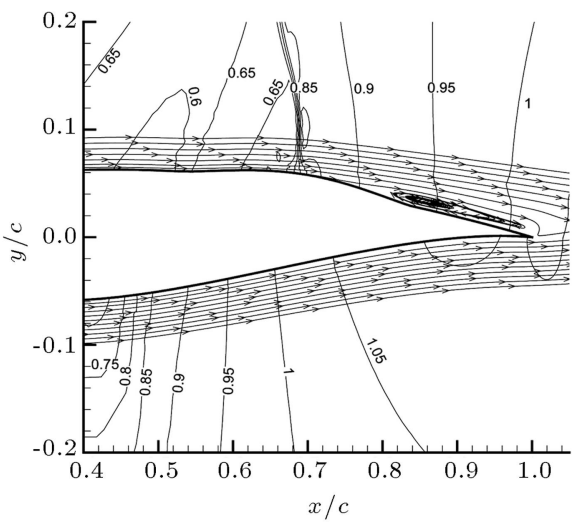

(d)

Figure 8. The flow streamlines and the pressure contours around RAE-2822 with optimized SCB: (a) $M_{\infty}=0.75$, (b) $M_{\infty}=0.76$, (c) $M_{\infty}=0.78$, and (d) $M_{\infty}=0.79$.

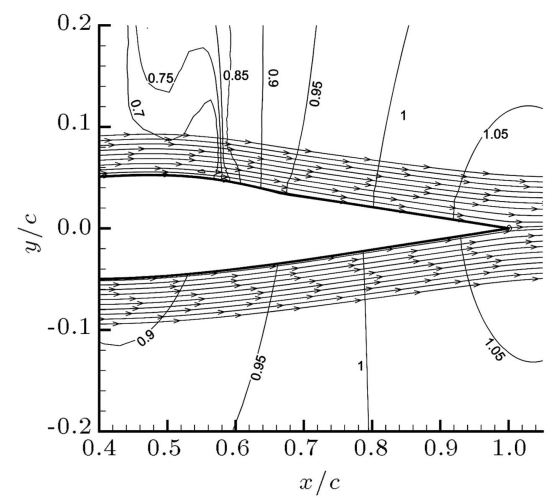

(a)

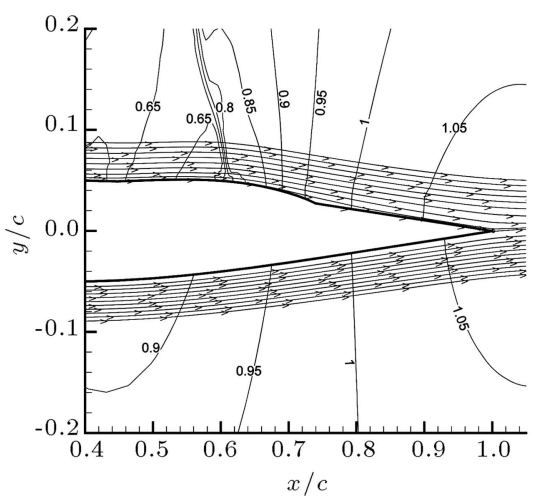

(b)

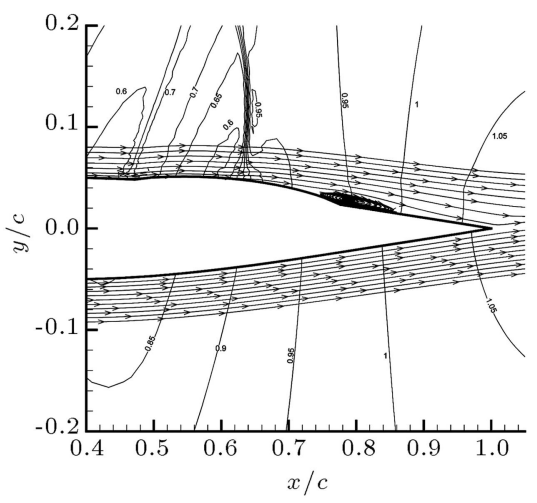

(c)

Figure 9. The flow streamlines and the pressure contours around NACA-64A010 with an optimized SCB: $\left(\right.$ a) $M_{\infty}=0.77$, (b) $M_{\infty}=0.786$, and (c) $M_{\infty}=0.81$. 
tion 4 according to Table 1 . We use a parametric study to find near optimum values of suction and blowing parameters. In this section, we will study the effect of three suction/blowing design parameters, i.e. mass flow, location, and the specific momentum, on the airfoil performance, and on the structure of the boundary layer and the vortical separated flow region.

First, we study the effect of the suction mass flow parameter on the aerodynamic coefficients of RAE2822 airfoil with the optimized SCB. The suction inlet width is $L_{s / b}=0.02 \mathrm{c}$, its location is $x_{s / b}=0.5 \mathrm{c}$ (located before the bump), and $\theta_{s / b}=-20^{\circ}$ relative to the chord line. Despite the last section, here, we are not trying to find the optimum values for suction. In fact, we are using a parametric study just to understand how suction affects different performance criteria, and to find the desirable values of the design parameters. Figure 10 shows variations of the aerodynamic coefficients and the efficiency with respect to the non-dimensional suction mass flow. The maximum lift and drag coefficients are achieved near $C_{Q} \approx-0.0018$ and $C_{Q} \approx-0.0014$, respectively, after which more suction results in decrease in both of them, while the aerodynamic efficiency increases as the non-dimensional mass flow increases. According to these results, the mass flow parameters in the range of $-0.003 \leq C_{Q} \leq-0.0035$ are the most desirable and after that, the lift coefficient loss is not practically acceptable.

In fact, the pressure variations in the suction region, although considered in the computation of the aerodynamic coefficients, are not important for us. Figure 11 shows pressure contours and streamlines for this case. Comparison of Figure 11(a) and (b) shows that the flow suction has not succeeded to eliminate the separation region behind the bump, despite reduction in the drag coefficient and increase in the efficiency.

Next, we will study addition of blowing after the $\mathrm{SCB}$ on RAE-2822 airfoil. This time, $\Theta_{s / b}=0^{\circ}$ (parallel to the chord line), its starting point is at $x_{s / b}=0.85 \mathrm{c}$ (located after the bump location), and the blowing width is $L_{s / b}=0.02 \mathrm{c}$. Results are shown in Figure 12. The maximum aerodynamic efficiency occurs around $C_{Q} \approx 0.0015$ and the minimum drag and the maximum lift coefficient occur around $C_{Q} \approx$ 0.0011. According to these results, the most desirable range for the mass flow parameter in blowing in this location is $0.0013 \leq C_{Q} \leq 0.0015$.

Again, the pressure distribution around the blowing region is not important for us. Figure 13 also shows
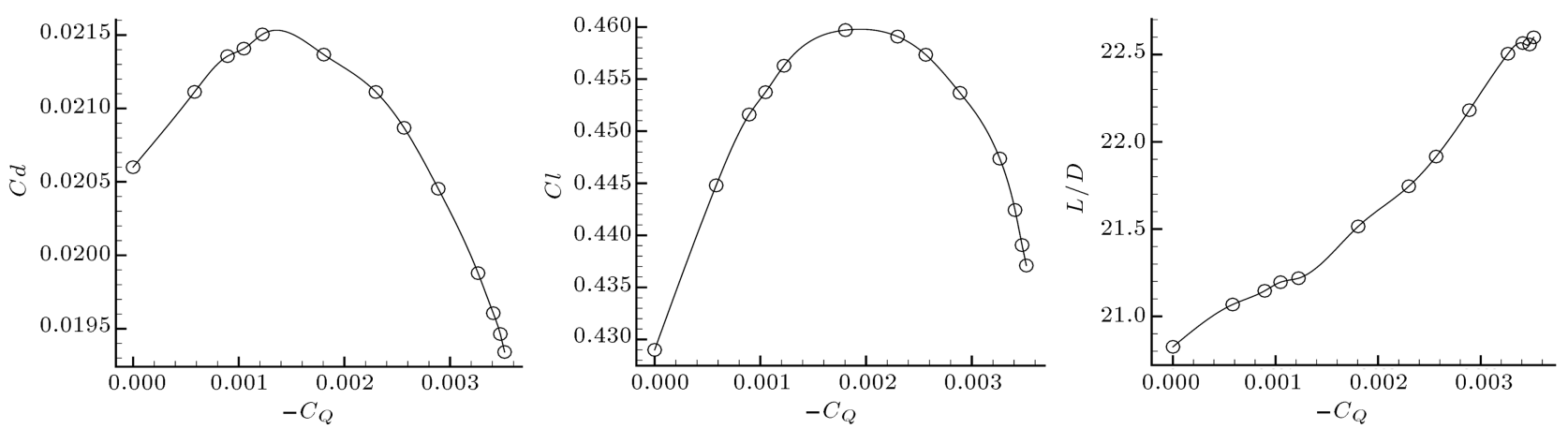

Figure 10. The aerodynamic coefficients and efficiency variations with respect to the non-dimensional suction mass flow at $x_{s / b}=0.5 \mathrm{c}$ for RAE-2822 with an optimized SCB at flight condition 4 .

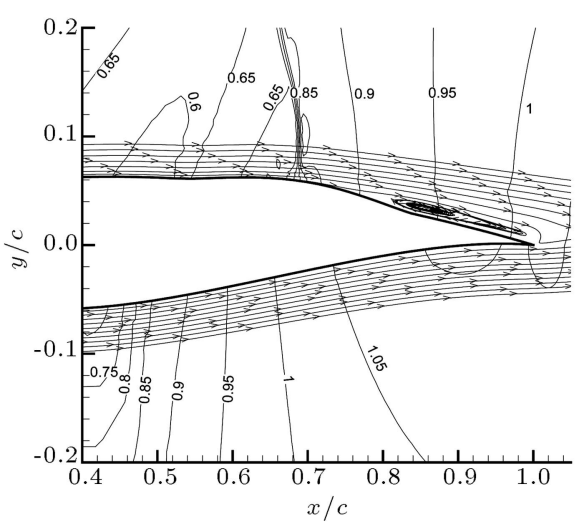

(a)

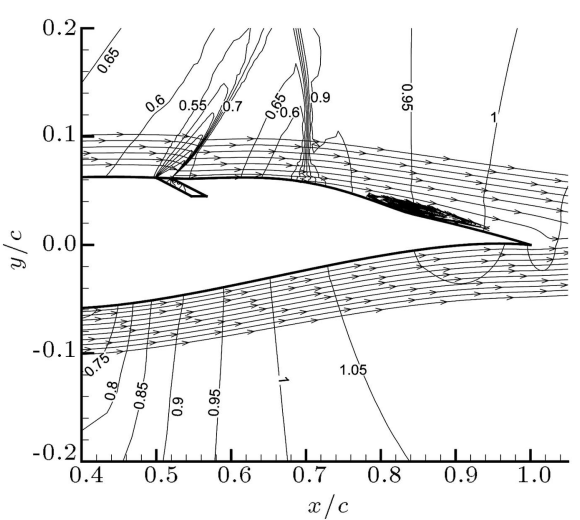

(b)

Figure 11. The flow streamlines with the pressure contours around RAE-2822 with an optimized SCB in flow condition 4: (a) Without suction, and (b) with suction at $x_{s / b}=0.5 \mathrm{c}$. 

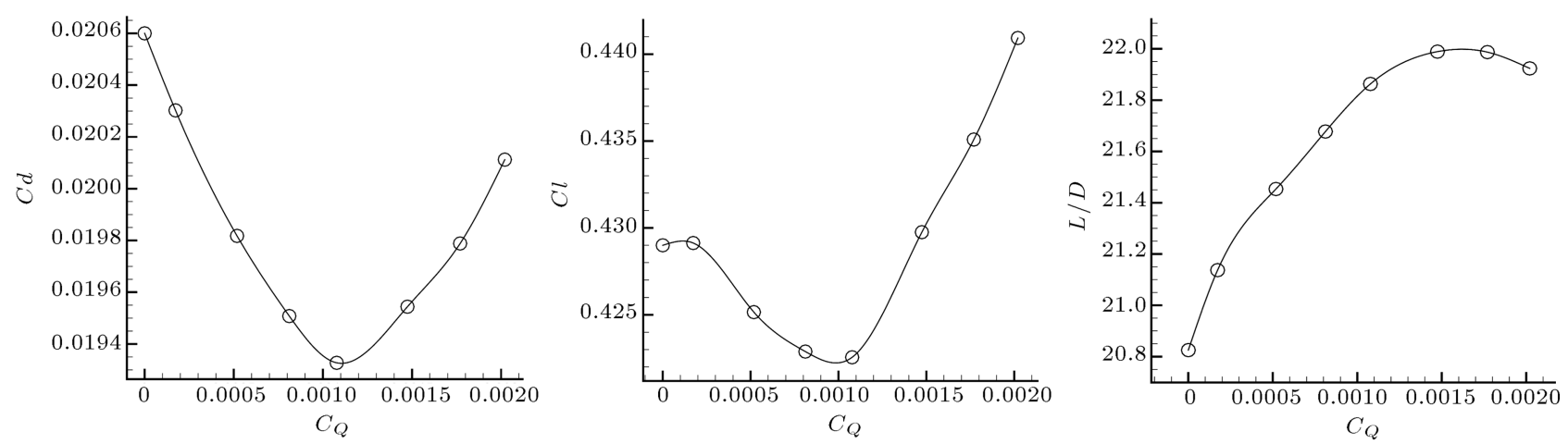

Figure 12. The aerodynamic efficiency and coefficient changes with respect to the non-dimensional blowing mass flow at $x_{s / b}=0.85$ c for RAE-2822 with an optimized SCB in flow condition 4 .

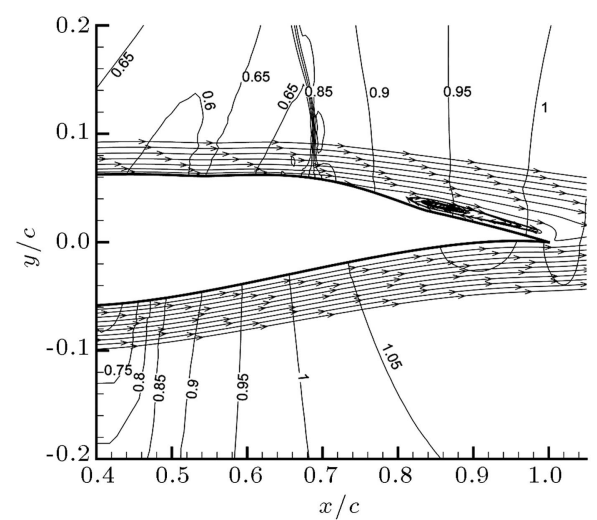

(a)

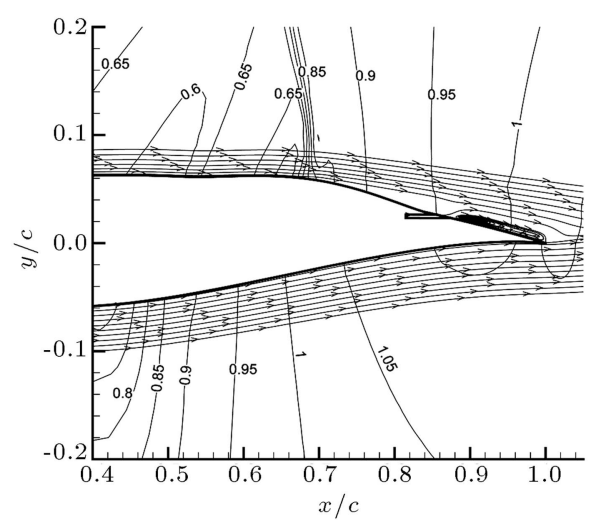

(b)

Figure 13. The flow streamlines with pressure contours around RAE-2822 with an optimized SCB in the flow condition 4 : (a) Without blowing, and (b) with blowing at $x_{s / b}=0.85 \mathrm{c}$.

pressure contours and streamlines for this case. The blowing flow has pushed the separated vortical flow towards the trailing edge, but has not still succeeded to remove it completely. Comparing Figures 11 and 13, one may observe that blowing is more effective in reducing the separated area behind the bump than a behind a suction.

We now study the effect of suction location on the aerodynamic coefficients and size of the separated region for RAE-2822, again at the flight condition 4 .
The non-dimensional mass flow is constant and is set to $C_{Q}=-0.0018$. The suction width is $L_{s / b}=$ $0.02 \mathrm{c}$ and its angle is $\Theta_{s / b}=-14^{\circ}$ relative to the chord line. The suction region is located before the shock wave. Figure 14 shows the variations of the aerodynamic efficiency and coefficients with respect to the suction location. It is illustrated that suction always results in increase of the lift coefficient. The maximum reduction in drag coefficient and increase in aerodynamic efficiency occur at $x_{s / b}=0.5 \mathrm{c}$.
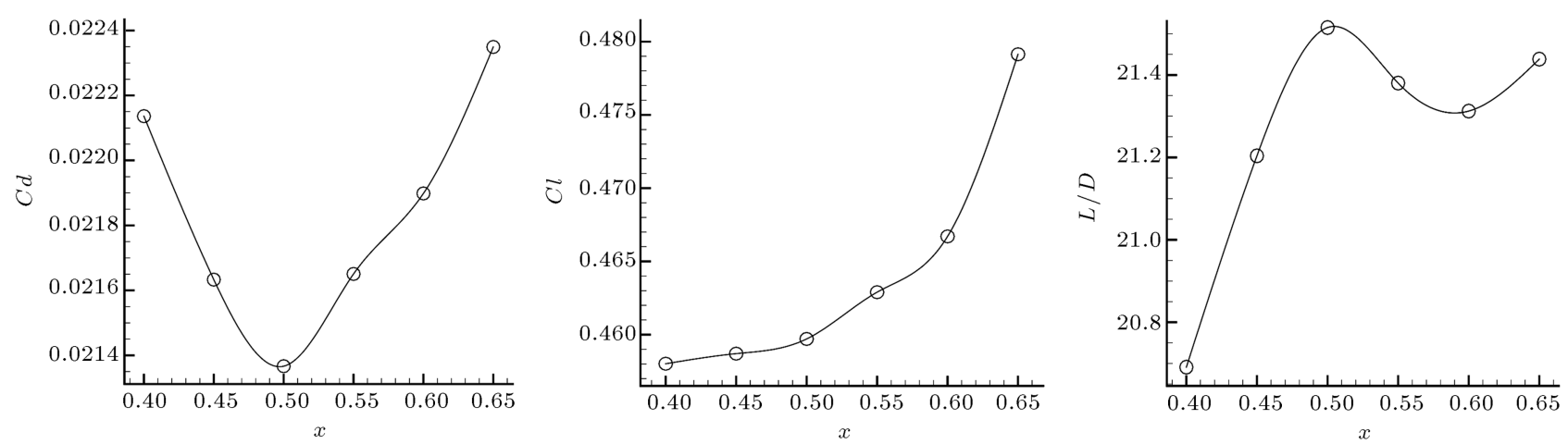

Figure 14. The RAE-2822 aerodynamic efficiency and variations of coefficients with respect to the suction location with $C_{Q}=-0.0018$. 

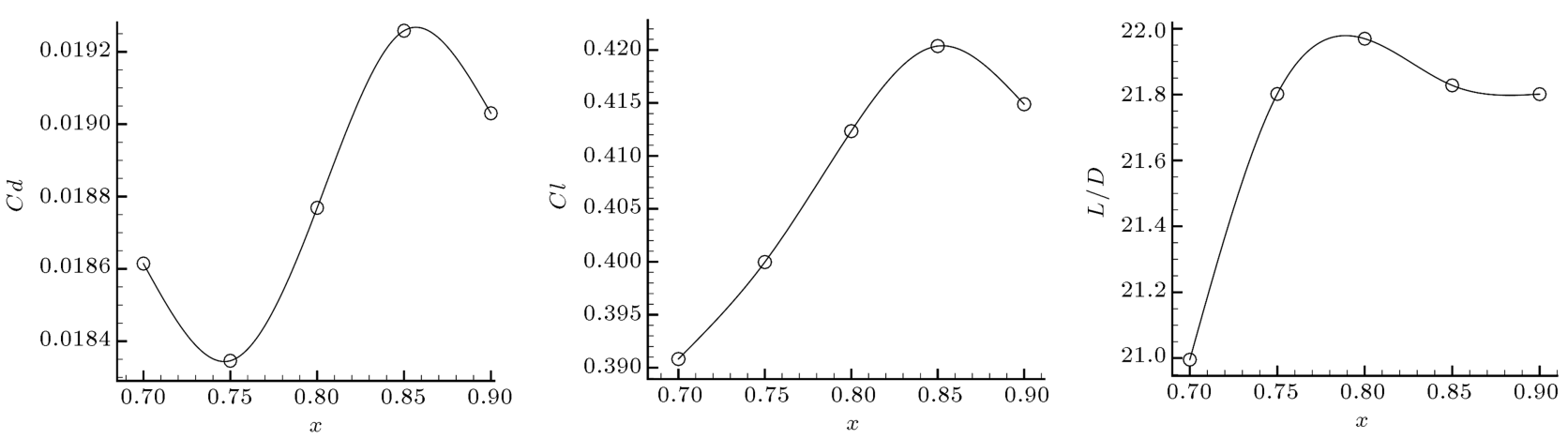

Figure 15. The RAE-2822 aerodynamic efficiency and variations of coefficients with respect to the blowing location with $C_{Q}=0.0011$.

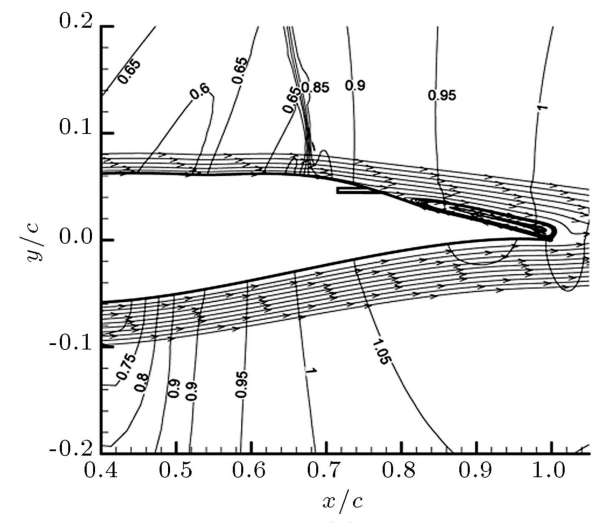

(a)

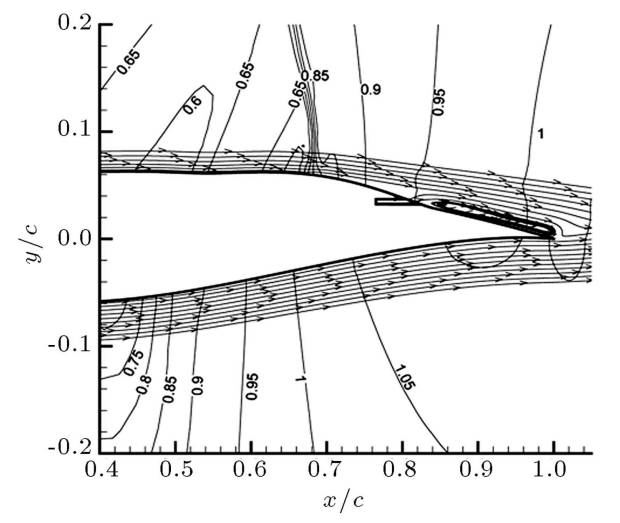

(b)

Figure 16. The flow streamlines around airfoil RAE-2822 with an optimized SCB in the flow condition 4 with blowing at two different locations: (a) $x_{s / b}=0.75 \mathrm{c}$ and b) $x_{s / b}=0.8 \mathrm{c}$.

Next, we study how blowing location may affect the results for RAE-2822 in the flight condition 4 in Table 1. The mass flow parameter is set to $C_{Q}=$ 0.0011. The blowing outlet width is $L_{s / b}=0.02 c$, its angle is $\Theta_{s / b}=0^{\circ}$ relative to the chord line, and it is located after the shock wave. Figure 15 shows the aerodynamic coefficients and efficiency variation with respect to the blowing position. The maximum efficiency improvement and the drag reduction occur at $x_{s / b}=0.8 \mathrm{c}$ and $x_{s / b}=0.75 \mathrm{c}$, respectively. Figure 16 shows the streamlines around RAE-2822 in the presence of bump and blowing in two different positions. The size of the vortical separated flow after the bump is reduced as the blowing position moves forward.

One may examine the boundary layer velocity profile, to better understand how suction or blowing changes the structure of the boundary layer and affects the interactions of the boundary layer and the shock wave. Figure 17 compares the boundary layer profiles over RAE-2822 at flight condition 4 for three different flow control schemes: the optimized SCB-only, the SCB with flow suction located at $x_{s / b}=0.5 \mathrm{c}$, and the SCB with flow blowing at $x_{s / b}=0.8 \mathrm{c}$. Profiles are shown in four stations before and inside the separated region, i.e. at $70,75,80$, and 85 percent of the chord length. This figure shows that the suction has resulted in a little thicker boundary layer, but the blowing makes the boundary layer thinner (in comparison with the RAE2822 with SCB-only). Also, note that the separated region is still present for both cases.

Another studied parameter is the flow specific momentum, or velocity. The suction mass flow parameter is set to $C_{Q}=-0.001$, and the flow angle is $\Theta_{s / b}=-20^{\circ}$ and it is located at $x_{s / b}=0.5 \mathrm{c}$. Figure 18 shows variations of aerodynamic coefficients with respect to the non-dimensional average velocity in the suction inlet. The maximum lift and drag coefficient and aerodynamic efficiency occur around $U_{\text {ave }} / U_{\infty} \approx 1.4$.

Similar studies were performed for blowing downstream of the SCB for RAE-2822 at flight condition 4. The mass flow parameter is set to $C_{Q}=0.001$. The angle is $\Theta_{s / b}=0^{\circ}$ relative to the chord line and its location is $x_{s / b}=0.8 \mathrm{c}$. Figure 19 shows variations of the aerodynamic efficiency and coefficients with respect to the non-dimensional average velocity of the outlet profile. One can see that increase in the outlet specific momentum results in the reduction of the aerodynamic efficiency and increase in the aerodynamic coefficients. A desirable value for this parameter is about 0.2 with respect to the aerodynamic efficiency values.

One always hopes that suction and blowing will 


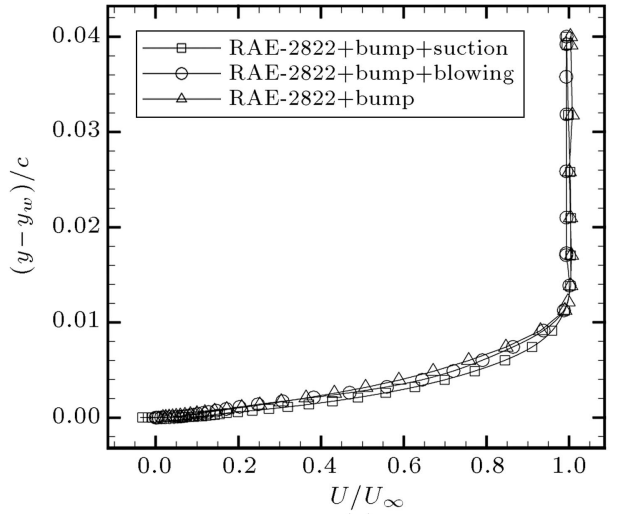

(a)

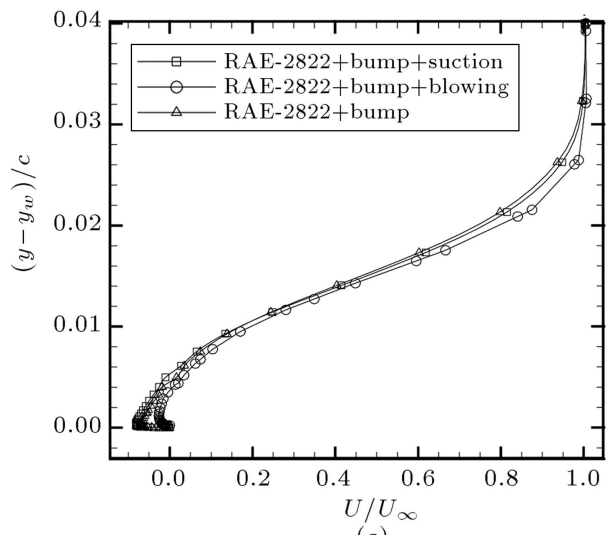

(c)

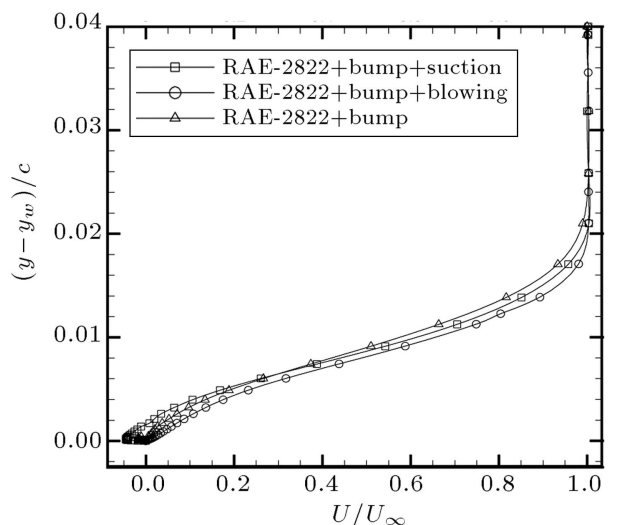

(b)

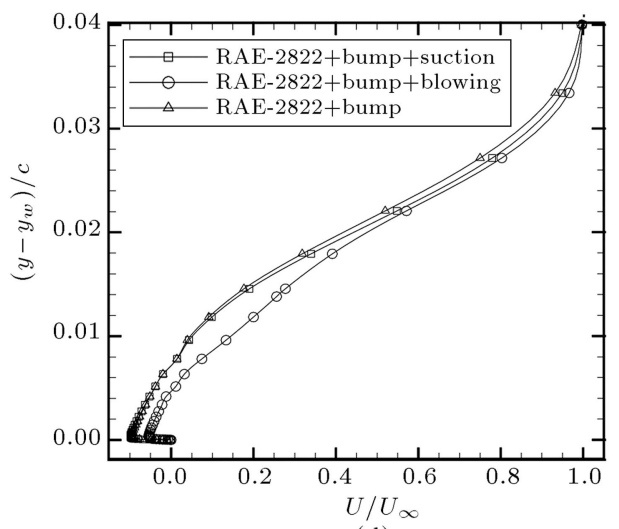

(d)

Figure 17. The velocity profiles over RAE-2822 + SCB with/without suction and blowing at the flight condition 4 at four different stations: (a) $x / c=0.7$, (b) $x / c=0.75$, (c) $x / c=0.8$, and (d) $x / c=0.85$.
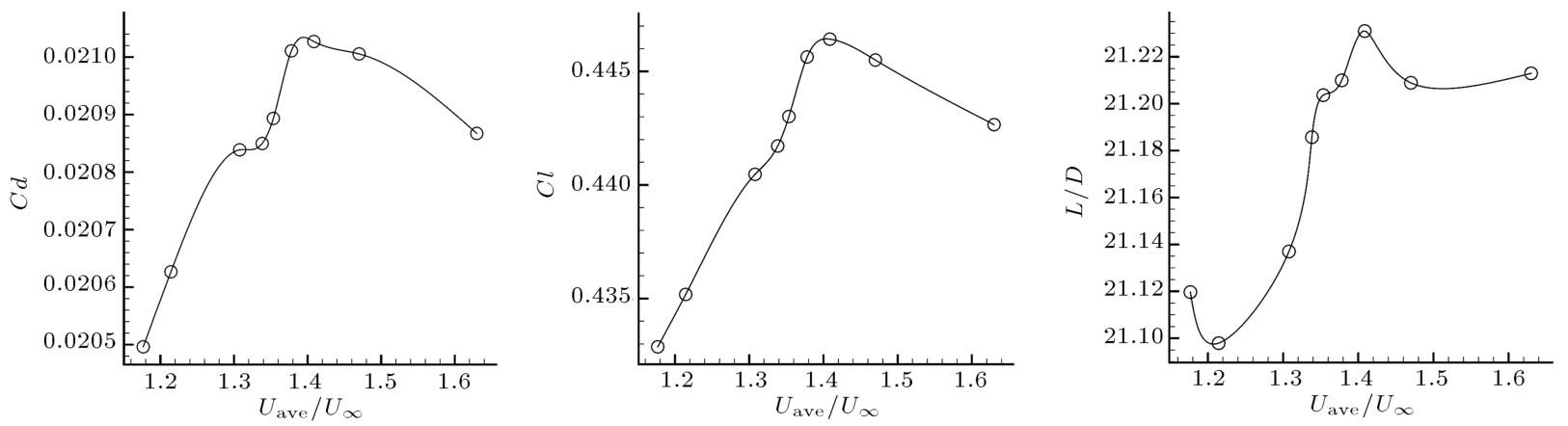

Figure 18. Aerodynamic efficiency and variations of coefficients with respect to the non-dimensional average velocity in the suction inlet for RAE-2822 with optimized SCB at flight condition 4 with $C_{Q}=-0.001$.
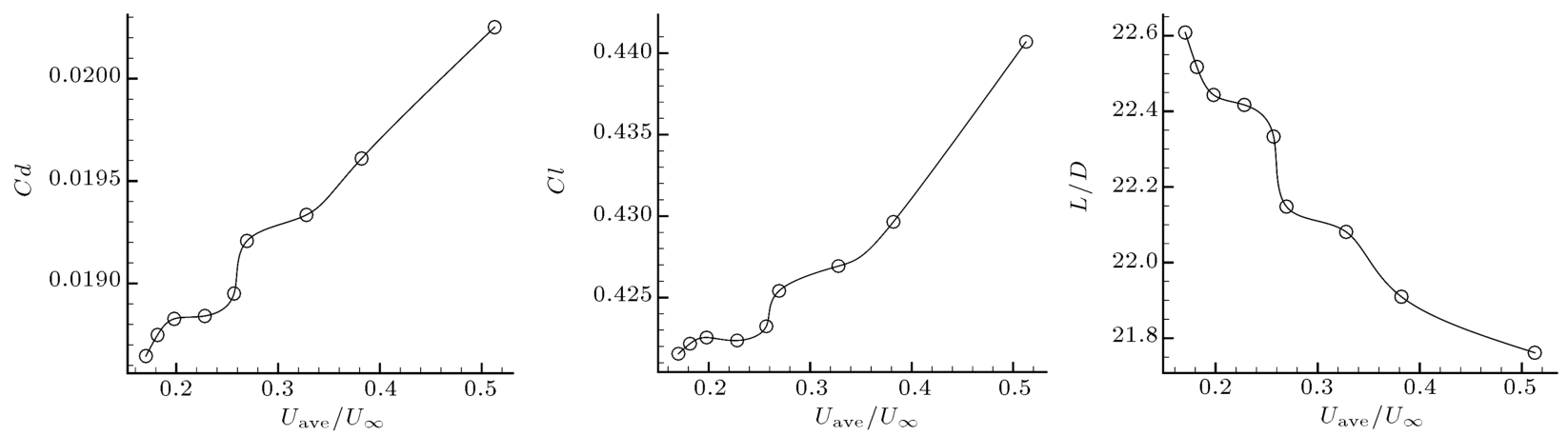

Figure 19. Aerodynamic efficiency and variations of coefficients with respect to the non-dimensional average velocity in the blowing outlet for RAE-2822 with optimized SCB at flight condition 4 with $C_{Q}=0.001$. 
reduce the size of the vortical separated region after the SCB. This may be favorable for many reasons, including the possibility of having control surfaces in the downstream part of the airfoil. The above results show that blowing is more effective than suction to remove (or to reduce) the separated region. Hence, it is feasible to remove the separated region by blowing after the shock wave. Obviously, decreasing the blowing angle results in a more effective jet and will energize the boundary layer stagnant flow more effectively. However, many practical issues remain to be examined later. To investigate this in more detail, we study effect of the mass flow parameter on the size and the structure of the separated flow region.

For RAE-2822 airfoil at flight condition 4, we set the blowing angle at $\Theta_{s / b}=0^{\circ}$ relative to the chord line, and the location at $x_{s / b}=0.75 \mathrm{c}$ with a channel width of $L_{s / b}=0.02 \mathrm{c}$. Table 10 shows that the maximum aerodynamic efficiency occurs at $C_{Q}=0.0025$ and this value is the maximum value achieved by blowing for the aerodynamic efficiency in this research. Figure 20 shows the resulting flow pattern, and confirms that by increasing the mass flow parameter, the vortical region becomes smaller and it eventually disappears. Higher aerodynamic efficiency
Table 10. Effect of the mass flow variation on the aerodynamic coefficients for RAE-2822 in flight condition 4 .

\begin{tabular}{cccc}
\hline $\boldsymbol{C}_{\boldsymbol{Q}}$ & $\boldsymbol{L} / \boldsymbol{D}$ & $\boldsymbol{C d}$ & $\boldsymbol{C l}$ \\
\hline 0.0 & 20.8 & 0.0206 & 0.429 \\
0.0012 & 22.3 & 0.0184 & 0.410 \\
0.0019 & 22.9 & 0.0181 & 0.415 \\
0.0022 & 23.5 & 0.0181 & 0.423 \\
0.0025 & 23.6 & 0.0184 & 0.434 \\
0.0029 & 23.5 & 0.0191 & 0.449 \\
\hline
\end{tabular}

and smaller separated region are two independent criteria for a wing designer. However, they usually correlate. It depends on the designer to select one of them or to use both.

\section{The suction/blowing for NACA-64A010 airfoil}

To generalize the results of the previous section for RAE-2822 to other airfoils, the suction and blowing mechanisms are also examined on NACA-64A010 airfoil for flight condition 3 in Table 2. The location of the suction region is considered before the bump at

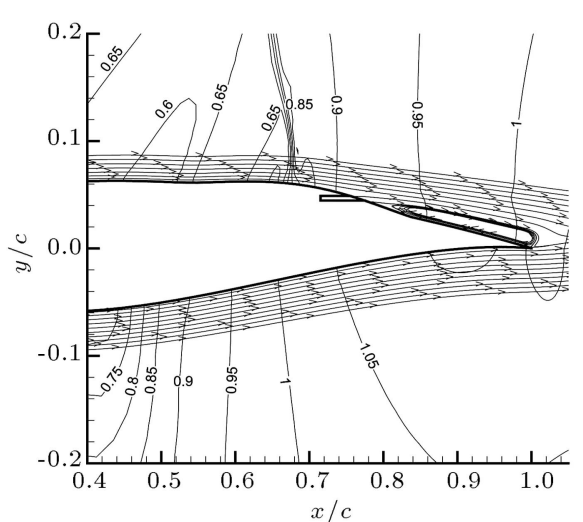

(a)

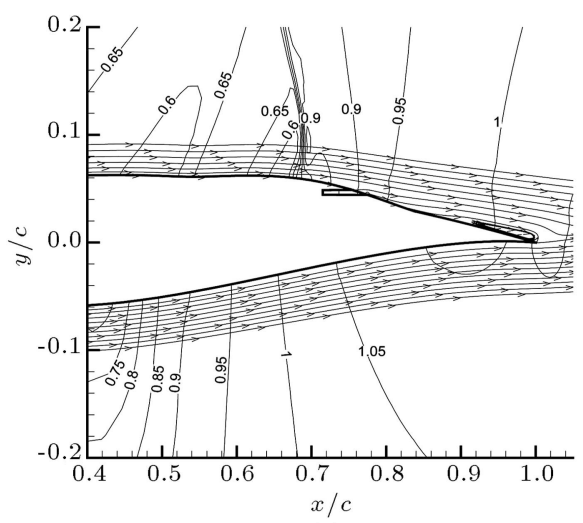

(c)

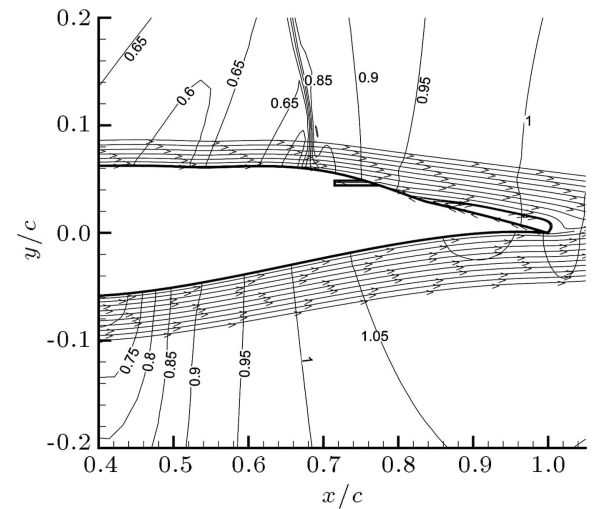

(b)

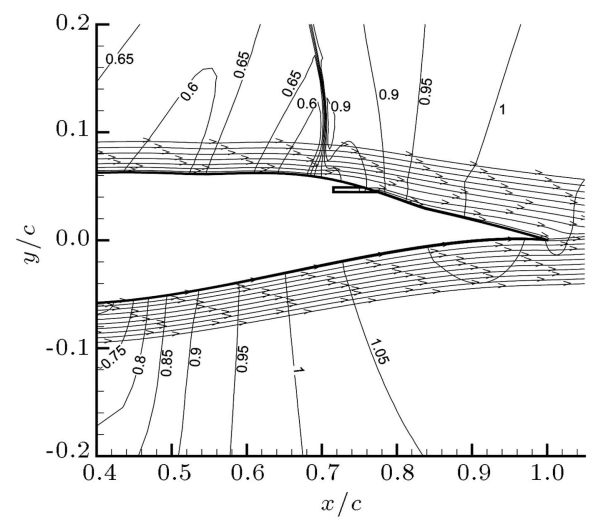

(d)

Figure 20. The flow streamlines around RAE-2822 with an optimized SCB in the flow condition 4 with blowing at $x_{s / b}=0.75 \mathrm{c}$ with various mass flow rates: (a) $C_{Q}=0.0012$, (b) $C_{Q}=0.0019$, (c) $C_{Q}=0.0022$, and (d) $C_{Q}=0.0029$. 
$x_{s / b}=0.45 \mathrm{c} ;$ a similar channel width of $L_{s / b}=0.02 \mathrm{c}$ is selected; and the angle is set to $\Theta_{s / b}=-20^{\circ}$ relative to the chord line. For suction, we make changes in the mass flow parameter by varying the suction channel outlet pressure. Figure 21 shows that the maximum lift and drag coefficient are achieved near $C_{Q} \approx-0.0014$, after which more suction results in lowering of both of them, while the aerodynamic efficiency increases as the non-dimensional mass flow increases. According to these results, similar to RAE2822 , mass flow parameters in the range of $-0.003 \leq$ $C_{Q} \leq-0.0035$ are the most desirable, and after that, the lift coefficient loss is not practically acceptable.

Again, details of the flow in the inlet of the suction channel are not important for us and we are only interested in hydrodynamic effects of this suction on the boundary layer structure over the whole airfoil surface. Figure 22 shows the pressure contours and the streamlines for this condition. One observes that despite the drag reduction and efficiency increase, suction has not completely eliminated the separated flow behind the bump, but has resulted in a smaller separated vortical flow behind the bump.

A similar study to consider effects of the blowing after the shock wave region on the boundary layer pattern for NACA-64A010 with SCB is also performed. This time, the angle is $\Theta_{s / b}=0^{\circ}$ relative to the chord line, its location is $x_{s / b}=0.7 \mathrm{c}$, and $L_{s / b}=$ 0.02c. The mass flow parameter varies by changing the blowing channel inlet pressure. Table 11 shows the results. Figure 23 shows that the lift coefficient increases as the mass flow parameter increases and the maximum aerodynamic efficiency happens around

Table 11. Effect of the mass flow variation on the aerodynamic coefficients for NACA-64A010 in flight condition 3 .

\begin{tabular}{cccc}
\hline $\boldsymbol{C}_{\boldsymbol{Q}}$ & $\boldsymbol{L} / \boldsymbol{D}$ & $\boldsymbol{C d}$ & $\boldsymbol{C l}$ \\
\hline 0.0 & 17.6 & 0.0189 & 0.333 \\
0.0003 & 17.9 & 0.0188 & 0.339 \\
0.0007 & 18.0 & 0.0183 & 0.329 \\
0.0012 & 18.6 & 0.0176 & 0.327 \\
0.0016 & 19.1 & 0.0176 & 0.335 \\
0.0018 & 19.1 & 0.0178 & 0.339 \\
0.002 & 19.2 & 0.0179 & 0.344 \\
0.0022 & 19.1 & 0.0183 & 0.35 \\
\hline
\end{tabular}
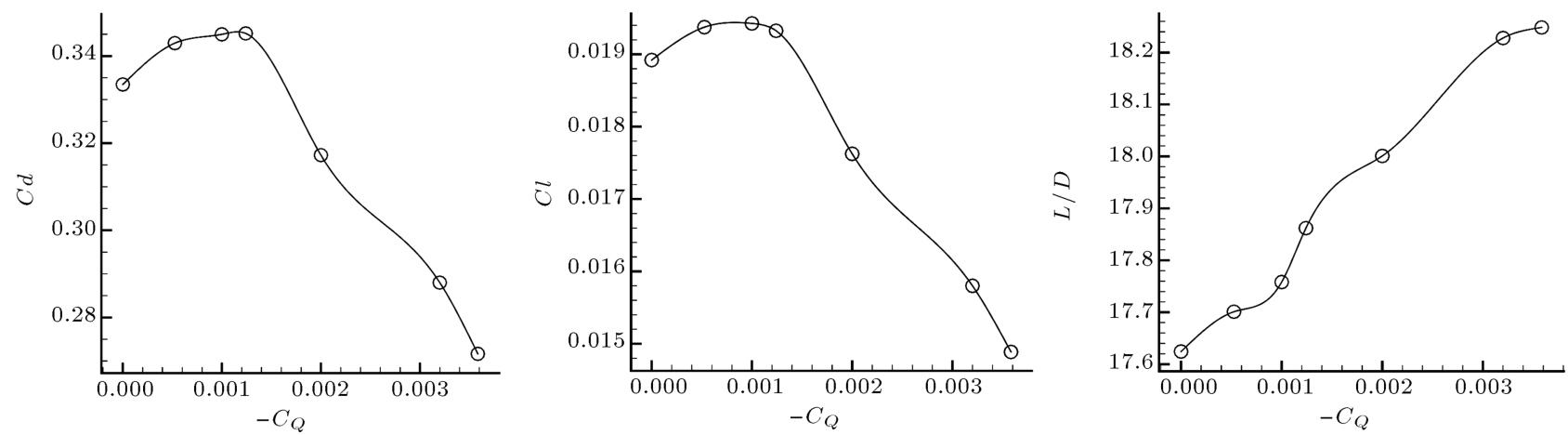

Figure 21. The aerodynamic efficiency and variations of coefficients with respect to the non-dimensional suction mass flow at $x_{s / b}=0.45 \mathrm{c}$ for NACA-64A010 at flight condition 3 .

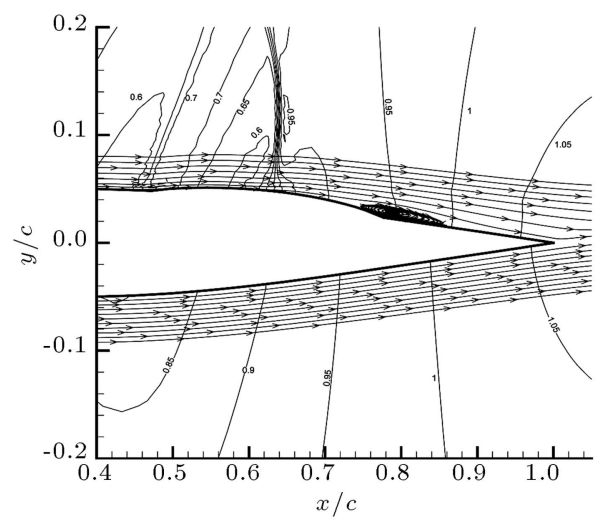

(a)

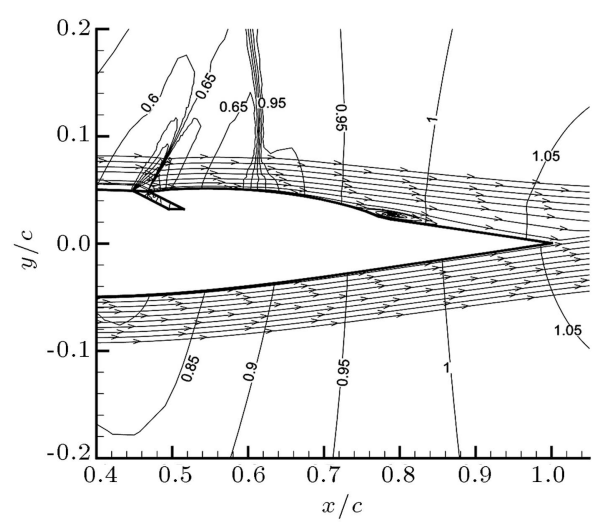

(b)

Figure 22. The flow streamlines with pressure contours around NACA-64A010 with an SCB in flow condition 3: (a) Without suction, and (b) with suction at $x_{s / b}=0.45 \mathrm{c}$. 

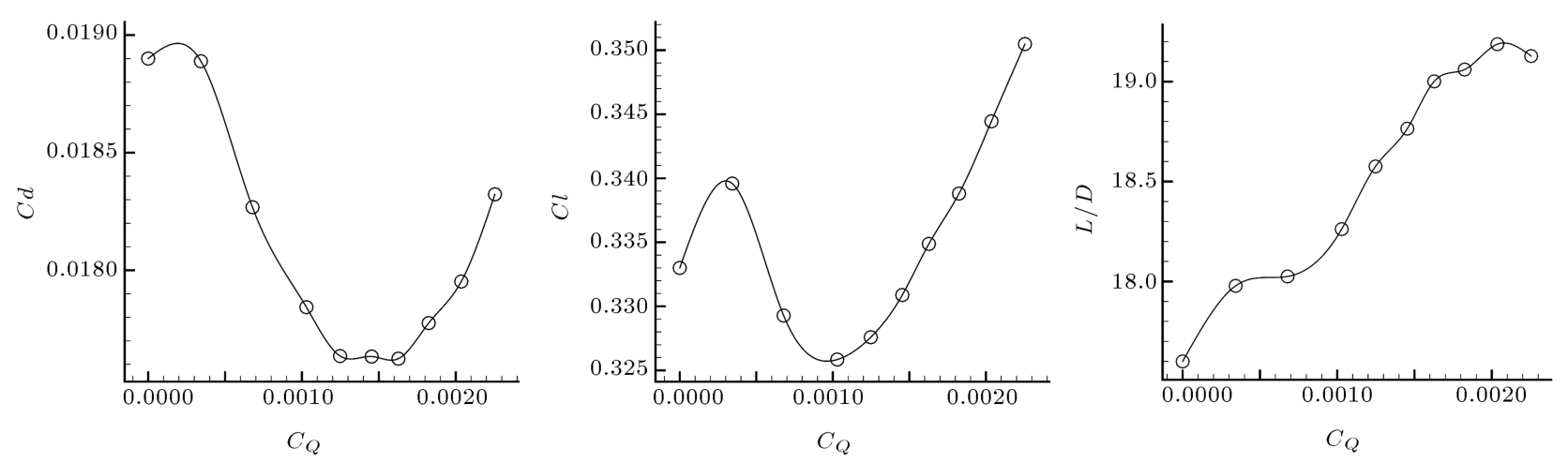

Figure 23. The aerodynamic efficiency and variations of coefficients with respect to the blowing mass flow parameter at $x_{s / b}=0.7 \mathrm{c}$ for NACA-64A010 at flight condition 3 .

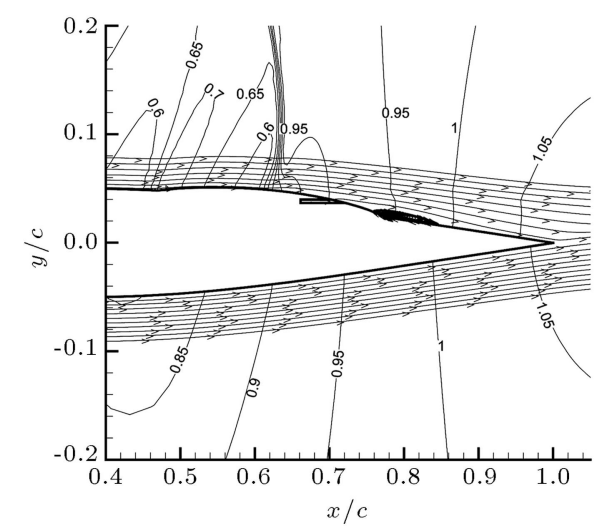

(a)

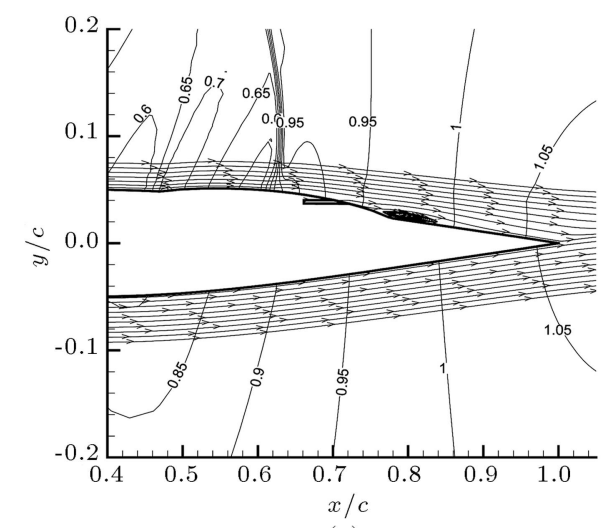

(c)

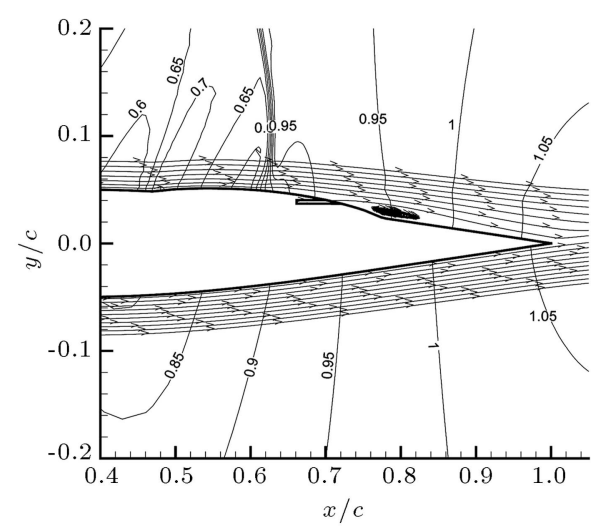

(b)

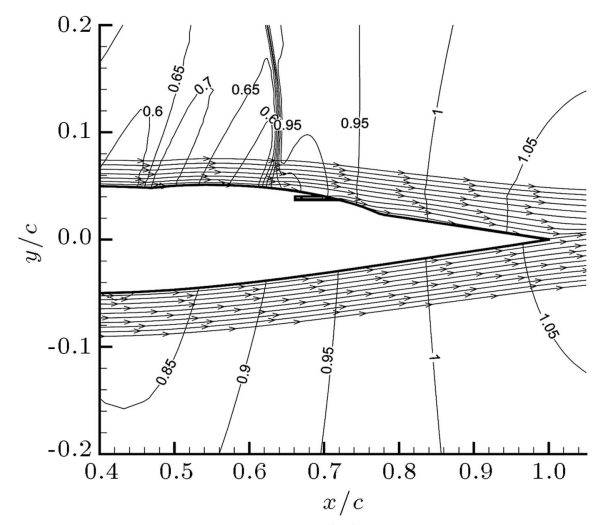

(d)

Figure 24. The flow streamlines around NACA-64A010 with an optimized SCB in the flow condition 3 with blowing at $x_{s / b}=0.7 \mathrm{c}$ with different mass flow rates: (a) $C_{Q}=0.0003$, (b) $C_{Q}=0.0007$, (c) $C_{Q}=0.0012$, and (d) $C_{Q}=0.0016$.

$C_{Q} \approx 0.002$ and the minimum drag coefficient happens around $C_{Q} \approx 0.0012$ in this location. One observes that the blowing after the SCB in NACA-64A010 airfoil is also more effective than the suction (see Figure 24). Increasing the mass flow again results in a smaller separated vortical flow behind the bump and, finally, this region is completely removed. The main result here is that all physical phenomena realized in this article for RAE-2822 airfoil are again observed for NACA-64A010 airfoil. This means that we may qualitatively generalize results in this article to all transonic airfoils in the region of off-design Mach numbers slightly after the drag divergence Mach number.

\section{Conclusions}

Many researchers have shown the effectiveness of SCBs to improve the aerodynamic performance of transonic wings. The optimization procedure may 
be used to find the optimized shape and location of $\mathrm{SCB}$, which has resulted in improvement of average aerodynamic efficiency by $23.6 \%$ for NACA-64A010 and $19.2 \%$ for RAE-2822 in their off-design conditions. However, these modifications result in large regions of separated flow, which may be unacceptable for design of the aerodynamic control devices. For stronger shock waves (higher Mach number flights), this nonlinear SWBLI results in larger separated regions with drastically deteriorating aerodynamic performance.

Here, we have added suction and blowing and have used a parametric study to control generation of large separated regions. For the RAE-2822 airfoil, we showed $8.6 \%$ improvement in the aerodynamic efficiency by the addition of suction upstream of the SCB, and another $13.5 \%$ improvement for application of blowing downstream of the SCB for flight condition 4. For NACA-64A010 airfoil, the improvement for suction is $3.9 \%$ and it is $9.0 \%$ for blowing in the free stream condition 3 .

These results show that blowing is more effective than suction for aerodynamic efficiency improvements (including both drag reductions and lift additions). In other words, most findings of this article and trends of results are generally applicable for most transonic airfoils. It was also shown that the best non-dimensional mass flow for suction is about -0.003 for both airfoils. The best non-dimensional mass flows for the blowing are about 0.0025 and 0.002 for RAE-2822 and NACA-64A010, respectively.

\section{Nomenclature}

\section{Abbreviations}

\section{$\mathrm{SCB}$}

Shock Control Bump

SWBLI Shock Wave/Boundary Layer

Interaction

HSS

Hybrid Suction/SCB

HBS Hybrid Blowing/SCB

\section{List of symbols}

$\begin{array}{ll}\mathbf{A}^{T} & \text { Jacobean of convective flux } \\ c & \text { Speed of sound } \\ C_{B} / l_{B} & \text { Bump degree of symmetry } \\ C d_{p} & \text { Pressure drag coefficient } \\ C d_{t} & \text { Airfoil drag coefficient } \\ C d_{v} & \text { Viscous drag coefficient } \\ C_{f} & \text { Skin friction coefficient } \\ C l & \text { Airfoil lift coefficient } \\ C_{p} & \text { Pressure coefficient } \\ C_{Q} & \text { Non-dimensional mass flow }\end{array}$

$\begin{array}{ll}d s & \text { Surface element } \\ E & \text { Total energy per unit mass } \\ f & \text { Hicks-Henne sine-function } \\ \mathbf{f}^{\text {inv }} & \text { Inviscid flux vector } \\ \mathbf{f}^{\mathrm{vis}} & \text { Viscous flux vector } \\ H & \text { Total enthalpy } \\ h_{B} & \text { Maximum bump height } \\ K & \text { Turbulent kinetic energy } \\ l_{B} & \text { Bump length } \\ L / D & \text { Aerodynamic efficiency } \\ M_{\infty} & \text { Free stream Mach number } \\ n_{x}, n_{y} & \text { Component of the unit normal vector } \\ p & \text { Static pressure } \\ P_{0} & \text { Total pressure } \\ P_{\infty} & \text { Free stream pressure } \\ q_{k} & \text { Heat flux } \\ \mathrm{Re}_{\infty} & \text { Free stream Reynolds number } \\ S & \text { The control volume surface } \\ S_{w} & \text { The airfoil surface } \\ t & \text { Bump slope parameter } \\ T & \text { Static temperature } \\ U_{\infty} & \text { Free stream velocity } \\ \mathbf{U} & \text { Vector of flow variable } \\ u, v & \text { Cartesian velocity component } \\ V & \text { Contra variant velocity } \\ x, y & \text { Cartesian coordinate system } \\ x_{0} & \text { Beginning of bump } \\ Y^{+} & \text {Non-dimensional wall coordinate } \\ \alpha & \text { Airfoil angle of attack (AoA) (deg) } \\ \gamma & \text { Ratio of specific heat coefficient } \\ \lambda & \text { Second viscosity coefficient } \\ \mu & \text { Dynamic viscosity coefficient } \\ \mu_{t} & \text { Turbulent viscosity coefficient } \\ \tau & \text { Shear stress across the control volume } \\ \tau_{k m} & \text { surface } \\ \rho & \text { Component of viscous stress tensor } \\ \omega & \text { Density } \\ & \text { Turbulent specific dissipation rate } \\ & \end{array}$

\section{References}

1. Milholen II, W.E. and Lewis L.R. "On the application of contour bumps for transonic drag reduction", In AIAA 43rd Aerospace Sciences Meeting and Exhibit, AIAA- 2005-0462, Reno (2005).

2. Patzold, M., Lutz., T.H., Kramer, E. and Wagner, S. "Numerical optimization of finite shock control bumps", In AIAA 44th Aerospace Sciences Meeting and Exhibit, pp. 9-12 Reno (2006). 
3. Stanewsky, E., Delery, J., Fulker, J. and de Matteis, P. (Editors) "Drag reduction by shock and boundary layer control", Results of Project EUROSHOCK II Supported by the European Union 1996-1999, Springer, Heidelberg (2002).

4. Ashill P.R. and Fulker, J.L. "A review of flow control research at dera", Fluid Mechanics and Its Applications, 53, pp. 43-56 (1999).

5. Mazaheri, K., Nejati, A., Kiani, K.C. and Taheri, R. "The application of the gradient-based adjoint multipoint optimization of single and double shock control bumps for transonic airfoils", International Journal on Shock Waves Detonations and Explosions, 42, pp. 196-208 (2015). http://dx.doi.org/10.1007/s00193015-0591-2

6. Mazaheri, K., Kiani, K.C., Nejati, A., Zeinalpour, M. and Taheri, R. "Optimization and analysis of shock wave/boundary layer interaction for drag reduction by shock control bump", Journal of Aerospace Science and Technology, 42, pp. 196-208, http://dx.doi.org/10.1016/j.ast.2015.01.007 (2015).

7. Qin, N., Zhu, Y. and Shaw, T.H. "Numerical study of active shock control for transonic aerodynamics", International Journal of Numerical Methods for Heat \& Fluid Flow, 14(4), pp. 444-466 (2004).

8. Bhattacharjee, S., Ahsan, M., Saha, M. and Moham$\operatorname{mad}$, M. "Numerical analysis of shock and boundary layer control over NACA0012 by contour bump, surface cooling and heating", Proceedings of the International Conference on Mechanical Engineering (ICME2007), Dhaka, Bangladesh (29-31 December, 2007).

9. Lee, D.S. et al. "Robust active shock control bump design using hyper parallel MOGA", Journal of Computational \& Fluids, 80, pp. 214-224 (2012).

10. Yagiz, B., Kandil, O. and Pehlivanoglu, Y.V. "Drag minimization using active and passive flow control techniques", International Journal of Aerospace Science and Technology, 17, pp. 21-31 (2012).

11. Vadillo, J.L., Agarwal, R.K. and Hassan, A.A. "Active control of shock/boundary layer interaction in transonic flow over airfoils", AIAA Paper 01-2975 (2001).

12. Tian, Y., Liu, P. and Feng, P. "Shock control bump parametric research on supercritical airfoil", Science China, 54(11:2935-2944), pp. 2935-2944 (November 2011).

13. Sommerer, A., Lutz, T. and Wagner, S. "Numerical optimization of adaptive transonic airfoils with variable camber", ICAS Congress (2000).

14. Wong, W.S., Le Moeing, A. and Qin, N. "Parallel adjoint-based optimization of a blended wing body aircraft with shock control bumps", The Aeronautical Journal, 111(1117), pp. 165-174 (March 2006).
15. Le Balleur, J.C., Girodroux-Lavigne, P. and Gassot, H. "Prediction of transonic airfoil/wing flow with control using a time-accurate viscous-inviscid interaction approach", Results of Project EUROSHOCK II Supported by the European Union 1996-1999, Third Annual Report (April 1999).

16. Pehlivanoglu, Y.V., Yagiz, B., Kandil, O. and Baysal, O. "Particle swarm optimization of suction and blowing on airfoils at transonic speeds", Journal of Aircraft, 47(6), pp. 1955-1965 (2010).

17. Pehlivanoglu, Y.V. and Yagiz, B. "Optimization of active/passive flow control parameters on airfoils at transonic speeds", Journal of Aircraft, 48(1), pp. 212219 (2011).

18. Birkemeyer, J. "Drag minimization on a transonic wing by ventilation and adaptive contour bump", DLR Research Report 1999-28, Ph.D. Thesis University Hannover (July 1999).

19. Qin, N., Zhu, Y. and Ashill, Pr., CFD Study of Shock Control at Cranfield, ICAS CONGRESS (2000).

20. Blazek J. "Computational fluid dynamics: Principles and applications", Elsevier, Computational Fluids \& Solid Mechanics, Printed in Netherlands, pp. 106-108 (2001).

21. Wilcox D.C., Turbulence Modeling for CFD, DCW Industries, Inc., La Canada, California (1998).

22. Ramezani, A. and Mazaheri, K. "Multi-grid convergence acceleration for implicit and explicit solution of Euler equations on unstructured grids", International Journal for Numerical Methods in Fluids, Inter Science Wiley Publication, 62(9), pp. 994-1012 (2009).

23. Lien, F.S. and Kalitzin, G. "Computations of transonic flow with $\nu 2-f$ turbulence model", Elsevier, Journal of Heat and Fluid Flow, 22, pp. 53-61 (2001).

24. Jameson, A., Leoviriyakit, K. and Shankaran, S. "Multi-point aero-structural optimization of wings including planform variations", In 45th Aerospace Sciences Meeting and Exhibit, AIAA-2007-764, Reno (2007).

\section{Biographies}

Karim Mazaheri is a Professor in the Faculty of Aerospace Engineering at Sharif University of Technology. He received his BSc degree at Sharif University of Technology in 1987, and his MSc and PhD degrees at the University of Michigan, in 1989 and 1992, respectively. His research interests are mainly in the area of CFD and aerodynamics, gas turbine system, propulsion, system engineering, and aviation strategic management.

Ashkan Nejati received his PhD degree in Aerospace Engineering from Sharif University of Technology in 2015. His research interests are mainly in the area of aerodynamic shape optimization, with special 
focus on optimization of compressor cascade; airfoils and wings; and, more recently, optimization of shock and boundary layer interaction control methods.

Kiarash Chaharlang Kiani received his MSc degree in Aerospace Engineering from Sharif University of Technology in 2012. He is currently a PhD student in Aerospace Engineering at Sharif University of Technology. His research interests are mainly in the area of film cooling, with special focus on application of film cooling in the cascade of turbine. 